Prepared for the National Aeronautics and Space Administration

\title{
Geologic Map of Jezero Crater and the Nili Planum Region, Mars
}

By Vivian Z. Sun and Kathryn M. Stack

Pamphlet to accompany

Scientific Investigations Map 3464

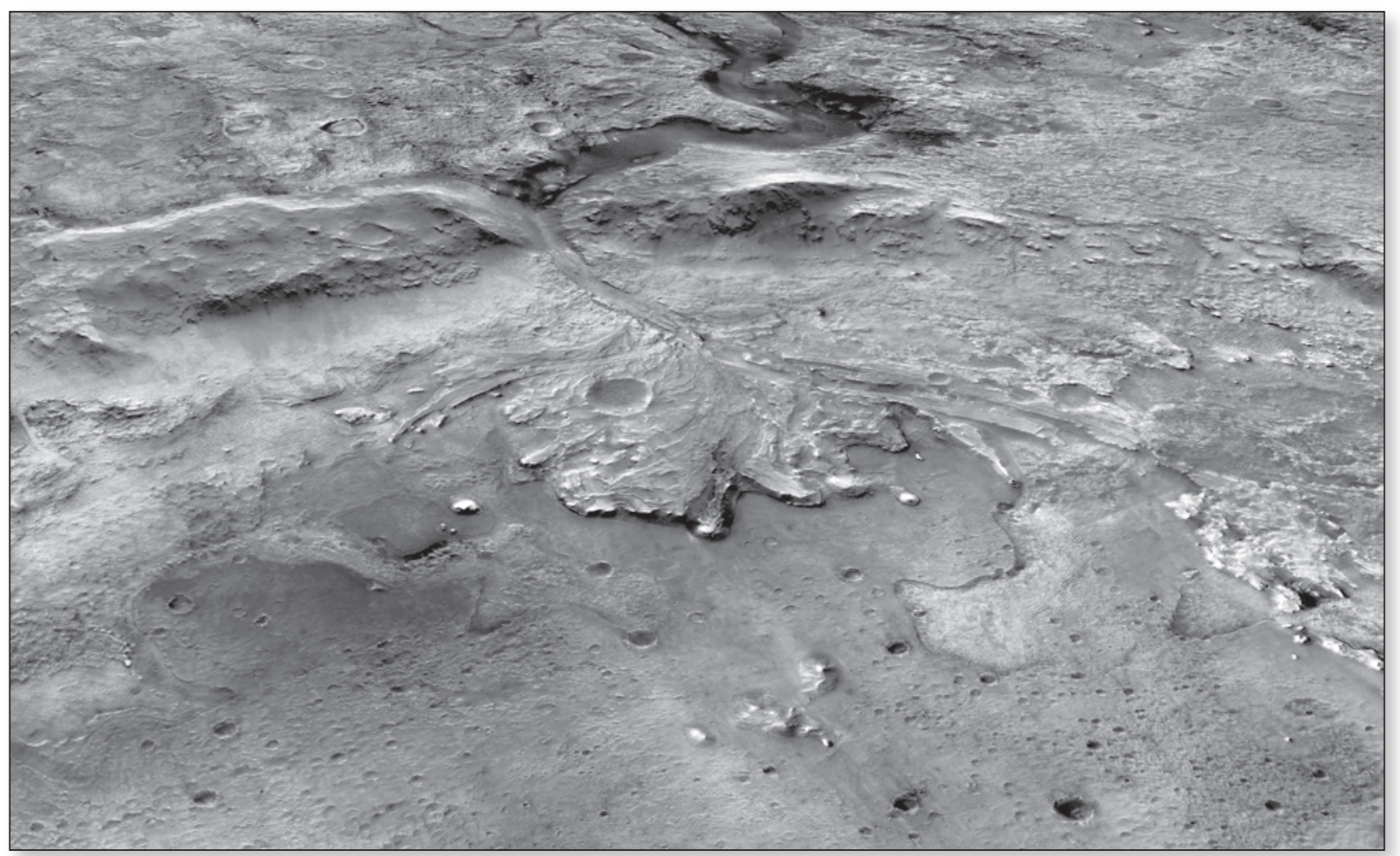

U.S. Department of the Interior

U.S. Geological Survey 


\title{
U.S. Department of the Interior DAVID BERNHARDT, Secretary
}

\author{
U.S. Geological Survey \\ James F. Reilly II, Director
}

\section{U.S. Geological Survey, Reston, Virginia: 2020}

For more information on the USGS - the Federal source for science about the Earth, its natural and living resources, natural hazards, and the environment-visit https://www.usgs.gov or call 1-888-ASK-USGS.

For an overview of USGS information products, including maps, imagery, and publications, visit https://store.usgs.gov.

Any use of trade, firm, or product names is for descriptive purposes only and does not imply endorsement by the U.S. Government.

Although this information product, for the most part, is in the public domain, it also may contain copyrighted materials as noted in the text. Permission to reproduce copyrighted items must be secured from the copyright owner.

Suggested citation:

Sun, V.Z., and Stack, K.M., 2020, Geologic map of Jezero crater and the Nili Planum region, Mars: U.S. Geological Survey Scientific Investigations Map 3464, pamphlet 14 p., 1 sheet, scale 1:75,000, https://doi.org/10.3133/sim3464.

ISSN 2932-1311 (print)

ISSN 2932-132X (online)

Cover. View of the northern part of the map area, highlighting the Jezero crater floor and delta deposit in the foreground and Neretva Vallis and the Nili Planum terrains in the background. Jezero crater is the anticipated landing site of the Mars 2020 Perseverance rover. 


\section{Contents}

Introduction

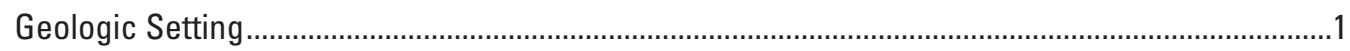

Previous Maps

Base Map and Data

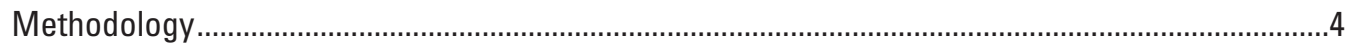

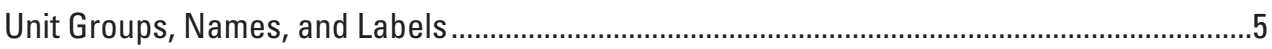

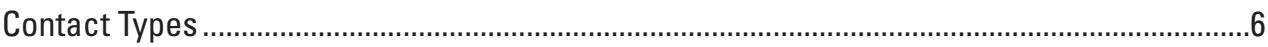

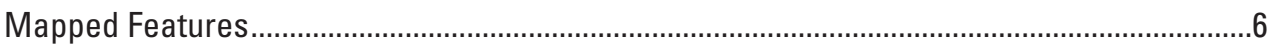

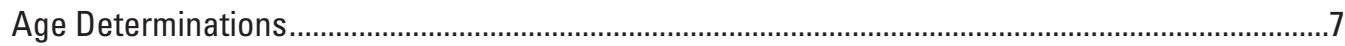

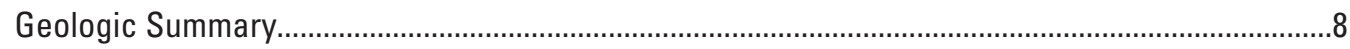

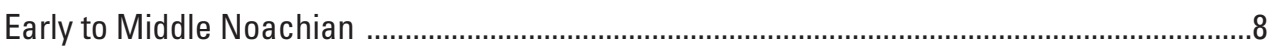

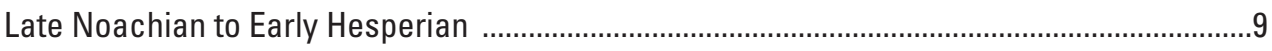

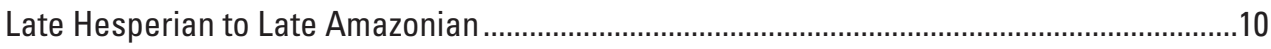

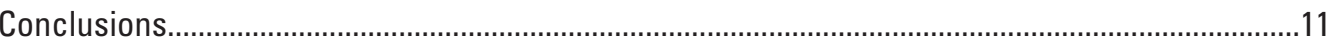

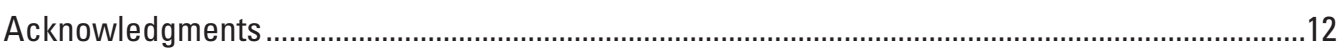

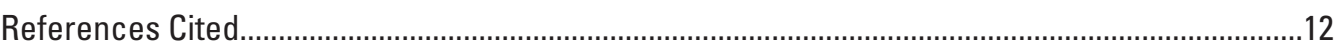

\section{Figures}

1. THEMIS daytime infrared mosaic with colorized MOLA topography, showing the regional context for the map area ..................................................................map sheet

2. CTX mosaic with colorized HRSC topography of the map area..........................map sheet

3. HiRISE images showing the various textures present in the upper etched unit (Nue): $A$, the ridged surface located in northwestern Jezero; $B$, the heavily cratered surface located in northern Nili Planum; and $C$, the light-toned rugged surface located in southern Nili Planum map sheet

4. HiRISE image with colorized CTX stereo topography showing an example of the

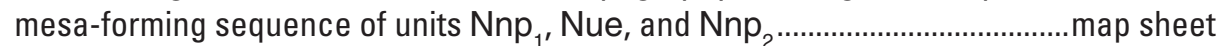

5. CTX images showing the various textures present in unit $\mathrm{Nnp}_{1}$. A, Unit $\mathrm{Nnp}_{1}$ typically has rugged topography juxtaposed with smoother surface textures. $B$, A very rugged, mound-forming outcrop of $\mathrm{Nnp}_{1}$ is adjacent to light and dark smooth surface textures of $\mathrm{Nnp}_{1}$. C, The smooth $\mathrm{Nnp}_{1}$ texture typically exhibits a dark tone but may also appear in lighter tones. map sheet

6. HiRISE images with colorized CTX stereo topography showing examples of unit Nrb mounds in Jezero crater $(A)$ and in Nili Planum $(B)$. map sheet

7. A, CTX basemap with colorized HRSC topography showing the Jezero delta (unit $\mathrm{NHjf}_{2}$ ). $B$ and $C$, HiRISE images with colorized CTX stereo topography showing the superposition relations between different delta lobes. map sheet

\section{Table}

1. Identification numbers of the supplemental HiRISE dataset used to map megabreccia locations and identify additional characteristics of map units. 


\title{
Geologic Map of Jezero Crater and the Nili Planum Region, Mars
}

\author{
By Vivian Z. Sun' and Kathryn M. Stack'
}

\section{Introduction}

The cratered highlands located northwest of Isidis Planitia have been recognized as one of the best preserved Noachian ( 3.7-4.1 Ga; Nimmo and Tanaka, 2005) landscapes currently exposed on Mars; they host some of the most diverse hydrated mineral assemblages detected on the planet (for example, Ehlmann and others, 2008a,b, 2009; Mustard and others, 2009). Numerous studies of the geomorphology, stratigraphy, and mineralogy in this region (for example, Hiesinger and Head, 2004; Fassett and Head, 2005; Mangold and others, 2007; Schon and others, 2012; Ehlmann and Mustard, 2012; Goudge and others, 2015; Bramble and others, 2017; Salvatore and others, 2018) have contributed to major advances in Mars science, such as helping to establish the paradigm of past abundant liquid water at the surface and near subsurface of early Mars during the Noachian period (for example, Scott and Carr, 1978; Pieri, 1980; Carr and Clow, 1981; Baker, 1982; Squyres and Kasting, 1994; Bibring and others, 2006; Mustard and others, 2008).

The geologic and mineralogic diversity of the region located northwest of Isidis basin makes it a high priority for landed mission exploration. The region contained three of the eleven top landing-site candidates for the currently active Mars Science Laboratory mission (Nili Fossae, northeast Syrtis Major, Jezero crater; Golombek and others, 2012). It also contained three of the final four landing-site candidates for the Mars 2020 mission (northeast Syrtis Major, Jezero crater, Midway). The 45-km-diameter Jezero crater was ultimately selected as the landing site for the Mars 2020 Perseverance rover (Grant and others, 2018; Fourth landing site workshop for the Mars 2020 rover mission, 2018). We present a continuous geologic map of Jezero crater and Nili Planum (informally referred to as northeast Syrtis in the literature) and provide a regional geologic framework linking two potentially different habitable environments and facilitating future local-scale observations from both localities.

${ }^{1}$ Jet Propulsion Laboratory

\section{Geologic Setting}

The map area, which includes the Jezero crater and Nili Planum region, is located northwest of Isidis Planitia (fig. 1). Within the map area, Nili Planum contains a sequence of units that are present across the broader northwestern Isidis basin. At the base of this regional sequence are Early Noachian rocks and sediments bearing signatures of low-calcium pyroxene and Fe/Mg phyllosilicates (Mustard and others, 2007, 2009; Ehlmann and Mustard, 2012) that were modified by the Isidis impact around 3.85-4.06 Ga (Schultz and Frey, 1990; Werner, 2009). An olivinerich unit overlies this Noachian basement unit and is hypothesized to be remnants of either Isidis basin impact melt (Mustard and others, 2007, 2009), subsequent volcanic flows (Hamilton and Christensen, 2005), or an ash-fall (Kremer and others, 2019) or pyroclastic-surge (Mandon and others, 2020) deposit. Portions of this olivine-rich unit were subsequently altered to $\mathrm{Mg}$-carbonate and, occasionally, serpentine (for example, Ehlmann and others, 2008a,b). A mafic, crater-retaining capping unit overlies the olivine-bearing unit (Mustard and others, 2009; Bramble and others, 2017). In the map area, the full regional sequence is most notably observed in southern Nili Planum, which contains mesas composed of the low-calcium pyroxene and $\mathrm{Fe} / \mathrm{Mg}$ phyllosilicatebearing Noachian basement, overlain by an olivine-rich unit, and capped by a mafic unit (Bramble and others, 2017).

The broader northwestern Isidis basin is incised with channels and contains fluvio-lacustrine landforms preserved within a number of topographic lows and craters, such as Jezero (for example, Fassett and Head, 2005; Mangold and others, 2007; Ivanov and others, 2012), with activity dated to the Late Noachian to Early Hesperian (Fassett and Head, 2008; Mangold and others, 2020). Within the map area, channels and deltaic or fan-shaped landforms are present within the northwest quadrant of Jezero crater and in northern Nili Planum. Of the channels associated with Jezero crater, the map area contains the western inlet channel, Neretva Vallis, whereas the northern inlet channel, Sava Vallis, and the eastern outlet channel, Pliva Vallis, lie outside of the map area.

Other major regional geologic events are marked by units and features that lie outside of the map area. The 3.85-4.06 Ga Isidis basin impact resulted in the formation of the concentric Nili Fossae graben (Greeley and Guest, 1987), which are located northwest of the map area and contain the aforementioned rock types that are 
present in southern Nili Planum (for example, Mustard and others, 2007). Southwest of the map area are high-calcium pyroxene-bearing Syrtis Major lavas, which were emplaced regionally during the Early Hesperian ( 3.5-3.8 Ga; Hiesinger and Head, 2004).

\section{Previous Maps}

The Jezero crater and adjacent Nili Planum region has been included in several past mapping efforts that varied in spatial extent, map scale, and scientific objectives. The earliest map of this region was published by Meyer and Grolier (1977) at 1:5,000,000 scale using Mariner 9 data. These researchers mapped part of the present-day Nili Planum region as cratered plains material (pc) and ridged plains material (pr) and interpreted these units as reworked basin ejecta and basaltic lava flows, respectively. Meyer and Grolier (1977) mapped the region immediately around Jezero crater as knobby material (k) and interpreted it as the erosional remnants of unit pc. They mapped the interior of Jezero crater as plains material (p) and interpreted the unit as a regolith and eolian mantle overlying the aforementioned units.

Scott and Carr (1978) published the first global map of Mars at 1:25,000,000 scale using Mariner 9 data. This map was the first to assign chronostratigraphic ages to units in this map region. These researchers mapped the Jezero crater and Nili Planum region as Hesperian and Noachian knobby material (HNk), which they interpreted as remnants of highland rocks and sediments and impact ejecta.

Greeley and Guest (1987) published a geologic map of the eastern equatorial region of Mars at 1:15,000,000 scale using Viking Orbiter images, which included the northwestern Isidis basin. These researchers mapped Jezero crater and Nili Planum as a Noachian etched unit (Nple) interpreted as a cratered unit that was mantled and eroded by eolian and, perhaps, some fluvial processes.

The map area is also contained in a map of the larger Isidis Planitia region produced by Ivanov and others (2012), who mapped the deposits within Jezero crater as Hesperian channeled materials (Hmch) because of their association with sinuous fluvial channels. They mapped the southern Jezero crater rim as Noachian subdued uplands (Nms), interpreted as ancient Noachian rocks that mass wasted from older massifs. Ivanov and others (2012) mapped the Nili Planum region as Noachian-Hesperian etched uplands (NHue) that they interpreted as diverse geologic materials that were variably eroded by eolian, fluvial, and (or) glacial processes.

Tanaka and others (2014) published an updated global geologic map at 1:20,000,000 scale using Mars Global Surveyor (MGS) Mars Orbiter Laser Altimeter (MOLA; Neumann and others, 2001) and Mars Odyssey (ODY) Thermal Emission Imaging System (THEMIS) daytime infrared data (Edwards and others, 2011). They mapped the northwestern Isidis basin as two units. The deposits within Jezero crater were mapped as part of a Hesperian and Noachian transition unit $(\mathrm{HNt})$, representing "Noachian impact breccias, sediments, and volcanic deposits" with contributions from Hesperian erosional products. Nili Planum was mapped as a Middle Noachian highland massif unit (mNhm) representing "crustal rocks uplifted by large, basin-forming impacts [dissected] by... fault structures and erosional valleys."
More recent mapping has specifically focused on mapping the Jezero crater and Nili Planum region using higher resolution datasets at larger map scales. Goudge and others (2015) mapped Jezero crater and its watershed at 1:30,000 scale on a Mars Reconnaissance Orbiter (MRO) Context Camera (CTX) base map, with the objective of assessing if the $\mathrm{Fe} / \mathrm{Mg}$ phyllosilicates and carbonates identified in the Jezero delta were sourced from mineralogically similar units exposed throughout the watershed outside the crater. They identified 28 geologic units within Jezero crater and its watershed, which contains part of the northern extent of Nili Planum (fig. 1). Goudge and others proposed a Jezero stratigraphic timeline beginning with the emplacement of the stratigraphically equivalent "light-toned floor" (LTF) and "mottled terrain" (MT) units after Jezero impacted into the regional basement, with unit LTF cropping out on the Jezero floor and unit MT cropping out both within Jezero and in its watershed region. Based on analysis of Compact Reconnaissance Imaging Spectrometers for Mars (CRISM; Murchie and others, 2007) data, both units LTF and MT contain olivine with variable contributions from $\mathrm{Mg}$-rich carbonate. Units LTF and MT compose part of the regional olivine-bearing unit that has been interpreted as Isidis basin impact melt, volcanic flows, or ash-fall or pyroclastic-surge deposits (Hamilton and Christensen, 2005; Mustard and others, 2007, 2009; Kremer and others, 2019; Mandon and others, 2020). The fan deposits, mapped as a "western fan deposit" (Fw) and a more heavily eroded "northern fan deposit" (Fn), lie stratigraphically above units LTF and MT. The deltaic or lacustrine origin of these fan deposits has been established by the presence of two inlet valleys (Neretva Vallis and Sava Vallis) and an outlet valley (Pliva Vallis) (fig. 1), suggesting that the deposits were emplaced into a hydrologically open lake environment (Fassett and Head, 2005; Ehlmann and others, 2008b; Schon and others, 2012; Goudge and others, 2015). Several studies have characterized the composition of the western fan deposit, identifying $\mathrm{Fe} / \mathrm{Mg}$ smectite (Ehlmann and others, 2008b) or Fe/Mg smectite with variable carbonate and olivine (Ehlmann and others, 2009; Goudge and others, 2015), where the olivine and carbonate appear to occur within interpreted point-bar deposits (Goudge and others, 2018; Horgan and others, 2020). The northern fan deposit contains olivine and carbonate with minor Fe/Mg smectite (Goudge and others, 2015; Horgan and others, 2020). The compositional difference between the fan deposits has been attributed to their detrital origins and different source regions, with the western fan deposit sourcing sediments from Neretva Vallis and the northern fan deposit sourcing sediments from Sava Vallis (Goudge and others, 2015). Goudge and others (2015) interpreted the next major event in Jezero to be the emplacement of the "volcanic floor" unit (VF), which was deposited on top of unit LTF and is suggested to embay the western and northern fan deposits (Schon and others, 2012; Goudge and others, 2015; Ruff, 2017). These characteristics, combined with its mafic composition, have led some to interpret unit VF as a volcanic flow (Schon and others, 2012; Goudge and others, 2015; Ruff, 2017), although sedimentary or volcaniclastic origins have alternatively been proposed (Sun and Stack, 2019).

Within the Jezero crater watershed that encompasses northern Nili Planum in the map area (fig. 1), Goudge and others (2015) mapped the lowest stratigraphic unit as the spectrally featureless "dusty, massive basement" unit (Bdm) representing the Noachian basement into which Jezero impacted. The "altered 
basement" unit (Bal) occurs stratigraphically above unit Bdm and contains $\mathrm{Fe} / \mathrm{Mg}$ smectite. The regional olivine-bearing unit MT was subsequently emplaced on top of unit Bal (Goudge and others, 2015). A "thin capping" unit (Tcu) was also mapped in small exposures along the western rim of Jezero's crater wall. Goudge and others (2015) also identified various younger units, representing surficial debris cover, impact crater structures and ejecta, and other fluvial deposits unrelated to the Jezero deposits.

Bramble and others (2017) mapped the region southwest of Jezero crater, including the southern Nili Planum region of the current map area (fig.1), identifying five major units with morphological heterogeneity. Bramble and others (2017) constructed their map at 1:1,000 and 1:5,000 scales using High Resolution Imaging Science Experiment (HiRISE) and CTX data, respectively, with the objective of assessing the geologic history and mineralogy of units exposed throughout the region. Bramble and others identified the "basement unit" (BAU) as the stratigraphically lowest unit, representing ancient Noachian crust. They subdivided unit BAU, which is generally associated with the presence of low-calcium pyroxene, Fe/Mg smectite, and rare kaolinite (Ehlmann and Mustard, 2012; Bramble and others, 2017) into subunits that contain mounds, knobby plains, smooth plains, and raised ridges. Megabreccia is also exposed throughout unit BAU (Bramble and others, 2017; Scheller and Ehlmann, 2020). Stratigraphically above unit BAU is the "fractured unit" (FRU), which Bramble and others (2017) noted is associated with an olivine composition that has been variably altered to $\mathrm{Mg}$ carbonate and represents a part of the regional olivine-bearing unit. They also mapped a "capping unit" (CAU) located stratigraphically above unit FRU. Unit CAU has been interpreted as a volcanic flow (Bramble and others, 2017) or ash fall or other sedimentary deposit (Bramble and others, 2017; Sun and Stack, 2019). Younger units in the current map area that were mapped by Bramble and others (2017) include eolian sediments and impact crater units.

During the selection process for the Mars 2020 landing site, Cofield and Stack (2018) and Sun and Stack (2018) produced higher-resolution, HiRISE-based maps for the proposed landing ellipses at Jezero crater (1:5,000 scale) and southern Nili Planum (1:1,000 scale), respectively. These two maps are of relatively small 10 by $8 \mathrm{~km}$ ellipse areas centered at lat $18.4^{\circ} \mathrm{N}$., long $77.5^{\circ} \mathrm{E}$. and lat $17.9^{\circ} \mathrm{N}$., long $77.2^{\circ} \mathrm{E}$., respectively. Both of these mapping efforts expanded on the preceding Goudge and others (2015) and Bramble and others (2017) maps at larger map scales by identifying additional textures and subunits that may inform the diversity of rocks and sediments encountered by a rover-scale investigation. Most recently, the Mars 2020 Science Team completed a collaborative mapping effort of the region around the Jezero crater landing ellipse at 1:5,000 scale (Stack and others, 2020). The Mars 2020 team-produced map identified surficial deposits and Jezero crater's delta deposits at a high level of detail, with the objective of establishing the stratigraphic framework for the scientific planning and investigation of Jezero crater with the Perseverance rover.

Previous mapping efforts have contributed to substantial improvements in our understanding of the geologic history of the Jezero crater and Nili Planum region, though none provided a continuous, high-resolution geologic map at uniform scale connecting the two locations. Such a map is important because Jezero crater and Nili Planum, while adjacent, have been interpreted to represent two distinct ancient habitable environments on Mars. Studies of Jezero crater have characterized it as a surface-habitable lacustrine environment on the basis of its preserved deltaic landforms, inlet and outlet channels, and hydrated mineralogy (for example, Fassett and Head, 2005; Ehlmann and others, 2008b; Schon and others, 2012; Goudge and others, 2015, 2017). In contrast, studies of southern Nili Planum have characterized it as a subsurface-habitable environment, because the region contains a sequence of geologic units bearing hydrated minerals in the absence of obvious or preserved links to fluvio-lacustrine processes (for example, Mustard and others, 2007, 2009; Ehlmann and others, 2009; Ehlmann and Mustard, 2012; Bramble and others, 2017). These differing interpretations persist despite Jezero crater and Nili Planum sharing geologic units that are similar in mineralogy and morphology (Bramble and others, 2017; Salvatore and others, 2018). Both sites contain $\mathrm{Fe} / \mathrm{Mg}$ phyllosilicate-bearing rocks as the stratigraphically lowest unit (Bdm, Bal in Goudge and others, 2015; BAU in Bramble and others, 2017), overlain by an olivine and carbonate-bearing unit (MT, LTF in Goudge and others, 2015; FRU in Bramble and others, 2017), and contain a capping unit (Tcu in Goudge and others, 2015; CAU in Bramble and others, 2017). Given the close proximity of these two areas, it is not improbable that the geologic units and history at both sites are related and can be investigated and characterized within the context of a continuous geologic map spanning both locations.

The objectives of this map are to enhance future scientific investigations of this region of Mars by (1) providing regional geologic context for the Mars 2020 and other potential future landed missions by helping to bridge regional and local observations, (2) connecting the geologic units across Jezero crater and Nili Planum and the history they imply, and (3) enabling the extrapolation of units that have been defined primarily by mineralogic composition to areas where no orbital spectroscopic data exists, because the distinct geologic units observed in this region appear to be strongly correlated to distinct mineral compositions (Bramble and others, 2017).

\section{Base Map and Data}

The map area contains both the majority of Jezero crater and Nili Planum at a map scale of 1:75,000, which was chosen to encompass the Jezero and southern Nili Planum landing sites at the time of project initiation. This map covers an area that is exactly $1^{\circ}$ by $1^{\circ}(\sim 60$ by $60 \mathrm{~km})$, spanning lat $17.7^{\circ}$ to $18.7^{\circ} \mathrm{N}$. and long $76.8^{\circ}$ to $77.8^{\circ} \mathrm{E}$. (fig. 2 ).

The primary base map used for this geologic map is composed of Mars Reconnaissance Orbiter's (MRO) Context Camera (CTX) images (Malin and others, 2007), compiled into a 6 meter per pixel (m/pixel) mosaic. We identified defining characteristics, boundaries, and stratigraphic relations of the mapped geologic units using the CTX basemap. Early in the mapping process, we also referenced the Mars Odyssey's nighttime Thermal Emission Imaging System (THEMIS) image mosaic (100 m/pixel mosaic; Christensen and others, 2004, 2013; Fergason and others, 2006). We created cross sections from 
digital terrain models (DTMs) constructed from CTX images (using stereo pairs B18_016575_1978 and B17_016219_1978 and J03_045994_1986 and J03_046060_1986; Fergason and others, 2017) at $20 \mathrm{~m} /$ pixel resolution. High-Resolution Stereo Camera (HRSC) topographic data from the Mars Express (MEX) orbiter (Fergason and others, 2018) also aided in the assessment of stratigraphic relations between units. Despite the relatively dense coverage of MRO High Resolution Imaging Science Experiment (HiRISE) images throughout this region and its higher resolution of $0.25-0.50 \mathrm{~m} / \mathrm{pixel}$ (McEwen and others, 2007), incomplete HiRISE coverage over the entire map area precluded the use of HiRISE images as the primary base map. However, we used HiRISE images, existing at the time of mapping (fig. 2; table 1), as a supplemental dataset to identify megabreccia exposures visible below CTX resolution (fig. 2) and to provide supporting characteristics for units below map resolution in the Description of Map Units and in the figures.

\section{Methodology}

To distribute mapping responsibilities between the two authors (Sun and Stack), we divided the map area into two halves along a diagonal line from the northeast to southwest corners of the map. We chose this division to ensure that each mapper had the opportunity to observe and characterize the full range of units in the map area, both within Jezero crater and in Nili Planum. We used a baseline set of units based on knowledge of previous mapping efforts (Goudge and others, 2015; Bramble and others, 2017) and mapped our respective areas with the type examples of these baseline units in mind, provisionally creating new unit designations for areas that did not conform to the baseline units. Periodic checks, when we compared representative examples of our respective map units, ensured that the same standards were being applied to distinguishing units in both map halves. We designated units that were mapped in both map halves and defined by the same characteristics as final map units for the combined map. We further assessed units that had differing characteristics or that we did not identify in both map halves to determine if that unit could be consolidated into another established map unit or if that unit was truly distinct and warranted designation as its own unit in the combined map. To facilitate later reconciliation of the map halves, we also specifically discussed the units to be mapped along the diagonal boundary. We then reconciled the two map portions into a single map by making minor adjustments to the contacts along the diagonal divide so that they were continuous while preserving the integrity of the mapped unit. Finally, Sun reviewed the entire combined map as a final check for consistency.

We performed all mapping and co-registration of datasets in a geographic information system (GIS). We projected datasets and shapefiles in the Transverse Mercator projection with a central meridian of $77.3^{\circ} \mathrm{E}$., with a planetocentric latitude and longitude increasing to the east. Points, lines, and polygons were digitized in the projected shapefiles. We digitized linework at a digital map scale of 1:20,000, which allowed for detailed placement of unit boundaries and contacts that would be visible at the publication map scale of 1:75,000. We streamed vertices
Table 1. Identification numbers of the supplemental HiRISE dataset used to map megabreccia locations and identify additional characteristics of map units, Jezero crater and Nili Planum region, Mars.

\begin{tabular}{|c|c|c|}
\hline HiRISE supplemental data & $\begin{array}{l}\text { Center latitude } \\
\text { (degrees) }\end{array}$ & $\begin{array}{c}\text { Center longitude } \\
\text { (degrees) }\end{array}$ \\
\hline PSP_002387_1985 & 18.488 & 77.404 \\
\hline PSP_002743_1985 & 18.54 & 77.49 \\
\hline ESP_015942_1980 & 17.818 & 77.112 \\
\hline ESP_016364_1980 & 17.892 & 77.288 \\
\hline ESP_016509_1980 & 17.822 & 77.21 \\
\hline ESP_016720_1980 & 17.785 & 76.924 \\
\hline ESP_016931_1980 & 17.809 & 77.03 \\
\hline ESP_017287_1980 & 18.204 & 77.056 \\
\hline ESP_022680_1985 & 18.23 & 77.435 \\
\hline ESP_022957_1985 & 18.348 & 77.619 \\
\hline ESP_023379_1985 & 18.345 & 77.525 \\
\hline ESP_024513_1980 & 18.018 & 76.895 \\
\hline ESP_034495_1990 & 18.688 & 77.662 \\
\hline ESP_036618_1985 & 18.517 & 77.281 \\
\hline ESP_037396_1985 & 18.46 & 77.371 \\
\hline ESP_037607_1990 & 18.615 & 77.574 \\
\hline ESP_037818_1990 & 18.568 & 77.452 \\
\hline ESP_045994_1985 & 18.427 & 77.437 \\
\hline ESP_048842_1985 & 18.464 & 77.517 \\
\hline ESP_049053_1980 & 17.883 & 77.15 \\
\hline ESP_049897_1980 & 17.992 & 77.059 \\
\hline ESP_052521_1985 & 18.187 & 77.119 \\
\hline ESP_053022_1985 & 18.224 & 77.187 \\
\hline ESP_053378_1985 & 18.252 & 77.132 \\
\hline ESP_053444_1985 & 18.337 & 77.055 \\
\hline ESP_053589_1985 & 18.18 & 76.978 \\
\hline ESP_053734_1985 & 18.275 & 77.317 \\
\hline ESP_053800_1985 & 18.168 & 76.903 \\
\hline ESP_053945_1985 & 18.231 & 77.252 \\
\hline ESP_054090_1985 & 18.469 & 77.103 \\
\hline ESP_054156_1985 & 18.49 & 77.034 \\
\hline ESP_055211_1985 & 18.443 & 77.227 \\
\hline ESP_055290_1985 & 18.458 & 77.365 \\
\hline ESP_055501_1985 & 18.188 & 76.977 \\
\hline
\end{tabular}

at a set vertex spacing of $75 \mathrm{~m}$ ( 1 vertex per 1 millimeter at 1:20,000 digital map scale). We then smoothed the linework using the Polynomial Approximation with Exponential Kernal with Tolerance algorithm and a tolerance of 40 meters (m). 
In this section, we describe (1) the identification and grouping, naming, and labeling of the map units, (2) the types of contacts employed in this map, and (3) the mapped point, line, and surface features. Although this text briefly refers to characteristics and interpretations of the map units and features as appropriate, we refer the reader to the Description of Map Units and Explanation of Map Symbols for more detailed descriptions of the mapped units and features.

\section{Unit Groups, Names, and Labels}

We defined map units on the basis of various characteristics visible in the CTX data at map scale, such as their texture, tone, morphology, marginal characteristics, geographic location, and stratigraphic relation to other units. We grouped the 14 map units according to their geographic location and regional occurrence as shown in the Description of Map Units. The Jezero crater units include four units that occur solely within Jezero crater: Jezero fan unit $1\left(\mathrm{NHjf}_{1}\right)$, Jezero fan unit 2 $\left(\mathrm{NHjf}_{2}\right)$, Jezero floor unit (Njf), and lower etched unit (Nle). The three Nili Planum units occur solely outside of Jezero crater in Nili Planum: Nili Planum unit $1\left(\mathrm{Nnp}_{1}\right)$, Nili Planum unit $2\left(\mathrm{Nnp}_{2}\right)$, and Nili Planum fan unit (Hnpf). Seven widely occurring units occur in both Jezero crater and Nili Planum: upper etched unit (Nue); rugged bright unit (Nrb); smooth undivided unit (su); eolian bedform unit (Aeb); and crater rim (cr), crater ejecta (ce), and crater interior (ci) units that correspond to the constituent rim, ejecta, and central interior bedrock components of an impact crater. We mapped only unit outcrops $>0.02 \mathrm{~km}^{2}$ to balance mapping consistency with clarity of the final map.

We named the map units based on their geographic location and their morphologic, textural, and stratigraphic characteristics compared to one another. The labels for each mapped unit, except for the crater ejecta, rim, and interior units, begin with an identifier for the chronologic period of unit formation $(\mathrm{N}$, Noachian; H, Hesperian; A, Amazonian). After unit age, unit labels include abbreviations of the full unit name. For the Jezero Crater and Nili Planum groups, the second abbreviation represents geographic occurrence in lowercase (j, Jezero crater; $n p$, Nili Planum). Specific unit designations describing stratigraphic order (I, lower; u, upper), associated landform ( $f$, fan; $f$, floor), and textural and albedo characteristics (s, smooth; r, rugged; $\mathrm{b}$, bright) are indicated by lowercase abbreviations. Numeric subscripts (Nili Planum 1 and 2; Jezero fan 1 and 2) indicate unit members where 1 is older and 2 is younger..

Units $\mathrm{NHjf}_{1}$ and $\mathrm{NHjf}_{2}$ form a sequence of fan deposits within Jezero crater, and we used a numeric designation to indicate that the fan unit 1 is topographically lower, and therefore older, than the fan unit 2. The lower etched unit (Nle), occurring only within Jezero crater, is the older, stratigraphically lower complement to the widely occurring upper etched unit (Nue). We interpreted that both units Nle and Nue have a similar origin based on their olivine-rich composition (Goudge and others, 2015) and their often gradational shared contact and that unit Nue was deposited conformably on top of unit Nle as part of the same depositional event. However, we mapped unit Nle as distinct from unit Nue to reflect that they occupy different elevations and stratigraphic intervals (for example, lat $18.63^{\circ} \mathrm{N}$., long $77.64^{\circ} \mathrm{E}$.) and that unit Nle may have been subsequently chemically and physically altered by lacustrine processes despite sharing a common origin with unit Nue.

Unit Nue contains three distinct surface textures (fig. 3): a ridged surface with northeast- to southwest-oriented ridges in northern Jezero and northeastern Nili Planum, a heavily cratered surface in northern Nili Planum, and a light-toned rugged surface that often forms large linear outcrops in southern Nili Planum. Though texturally distinct, these three surfaces grade from one to the other at map scale and are not always separated by clear topographic or stratigraphic contacts. We elected to map all three surface textures together as unit Nue, based on their contiguous nature and common stratigraphic position relative to other map units, and we attributed the cause of these distinct surface textures to differential erosion or cementation. However, to illustrate the three distinct surface textures on the map, we show the ridged surface in the northeastern portion of the map area with a hachured pattern to distinguish it from the heavily cratered surface. The heavily cratered surface occupies a large portion of northern Nili Planum, whereas unit Nue is sparser in southern Nili Planum as a light-toned rugged surface that forms long linear outcrops visible at map scale (for example, lat $17.78^{\circ} \mathrm{N}$., long $77.31^{\circ} \mathrm{E}$.).

In Nili Planum, units $\mathrm{Nnp}_{1}$ and $\mathrm{Nnp}_{2}$ commonly co-occur with unit Nue, forming the sequence of unit $\mathrm{Nnp}_{1}$ overlain by unit Nue, which is overlain by unit $\mathrm{Nnp}_{2}$ (fig. 4). Unit $\mathrm{Nnp}_{1}$ contains three dominant surface textures (fig. 5): a mound-forming surface, a rugged high-relief surface, and a smooth low-relief surface that frequently appears dark toned. The rugged $\mathrm{Nnp}_{1}$ surface contains irregular or poorly defined margins, that contrast with the well-defined margins of adjacent units Nue and $\mathrm{Nnp}_{2}$. Though outcrops of the rugged $\mathrm{Nnp}_{1}$ may also appear flat topped like unit $\mathrm{Nnp}_{2}$, unit $\mathrm{Nnp}_{2}$ is distinguished by its lobate margins and boulder-shedding texture, especially in HiRISE images, in contrast to the irregular and less-defined edges of the rugged $\mathrm{Nnp}_{1}$ unit (fig. 4). Unit $\mathrm{Nnp}_{2}$ also most commonly caps unit Nue (fig. 4) but may also directly overlay unit $\mathrm{Nnp}_{1}$ (for example, lat $18.12^{\circ} \mathrm{N}$., long $76.90^{\circ}$ E.) or the Jezero crater rim (unit cr; lat $18.39^{\circ} \mathrm{N}$., long $77.27^{\circ}$ E.), when unit Nue is absent or not apparent.

Some parts of unit $\mathrm{Nnp}_{1}$ form light-toned, rugged mounds (fig. $5 B$ ) that are similar to some outcrops of unit Nrb. However, we mapped these rugged mounds as part of unit $\mathrm{Nnp}_{1}$ owing to their contiguity with the smooth surface texture of unit $\mathrm{Nnp}_{1}$ and the onlapping of unit Nue along the sides of these mounds (fig. $5 B$ ). In contrast, unit Nrb occurs stratigraphically above unit Nue, because the latter is visibly exposed along the side of Nrb mounds, suggesting that unit Nrb was emplaced on top of unit Nue (fig. 6). We mapped other mounds along the west and south margins of the Jezero crater wall as unit $\mathrm{cr}$ and interpreted them as portions of the transient crater rim that have collapsed to form the terraced walls characteristic of complex craters (cross section $B-B^{\prime}$; Pilkington and Grieve, 1992). A crater rim interpretation for these mounds is supported by their stratigraphic occurrence beneath unit Nue, which onlaps them, and the occurrence of megabreccia within these mounds (lat $18.15^{\circ} \mathrm{N}$., long $77.53^{\circ} \mathrm{E}$; lat $18.29^{\circ} \mathrm{N}$., long $77.40^{\circ} \mathrm{E}$.), suggesting that these mounds are impact-generated products and may consist of the original target basement rock. 
The mound-forming, rugged, and smooth unit $\mathrm{Nnp}_{1}$ surfaces grade between one another without clear stratigraphic contacts (fig. $5 B$ ) and were therefore mapped together as unit $\mathrm{Nnp}_{1}$. To illustrate the spatial occurrence of these two surfaces in the map area, we mapped the dark-toned smooth $\mathrm{Nnp}_{1}$ surface with a dark-colored mantling material feature in areas where we interpreted that unit $\mathrm{Nnp}_{1}$ was preferentially mantled by an unconsolidated dark, smooth deposit. We also mapped the dark-colored mantle surface in portions of unit Njf, especially in regions adjacent to the fan unit $\mathrm{NHjf}_{2}$. We interpreted other regions containing smooth, intermediate- to dark-toned surfaces to be mantled by similar unconsolidated sediment, but we distinctly mapped these occurrences as unit su, if the mantling deposit appeared thick enough that the underlying unit cannot be determined.

Unit colors follow previous map convention where possible. We chose blue colors to represent fan units $\left(\mathrm{NHjf}_{1}\right.$, $\mathrm{NHjf}_{2}, \mathrm{Hnpf}$ ), following convention for basin units and units interpreted to be deposited by fluvial processes (for example, Scott and Carr, 1978; Tanaka and others, 2014). Earth tones correspond to extensive ancient highland units in Nili Planum $\left(\mathrm{Nnp}_{1}, \mathrm{Nle}, \mathrm{Nue}\right)$ and for crater units (cr, ce, ci), similar to convention set by the color schemes from previous Mars global maps (Scott and Carr, 1978; Tanaka and others, 2014). Colors for other units (for example, $\mathrm{Nnp}_{2}, \mathrm{Njf}$, Nrb) intentionally did not follow precedent, such as applying warm colors for volcanic units and cool colors for sedimentary units. This is because, at map scale, the remaining map units have properties that cannot be definitively attributed to either a volcanic or sedimentary origin.

\section{Contact Types}

We used certain and approximate contact types to indicate the degree of certainty of a mapped contact. A "certain" contact indicates when the distinction between two geologic units was clear and well defined. An "approximate" contact denotes where there was a transition between two defined geologic units, but the exact location of the contact could not be confidently identified due to the map scale or, most frequently, overlying surficial mantling or eolian deposits.

\section{Mapped Features}

We mapped morphologic features as point and line symbols where they could be singularly distinguished at map scale and as patterns where the features cover a broad area $(>0.02$ $\mathrm{km}^{2}$ ) and are relatively closely spaced. We represented these features on the map using symbols derived from the Federal Geographic Data Committee Digital Cartographic Standard for Geologic Map Symbolization (U.S. Geological Survey, 2006), with some adaptation to suit the features observed in the map area. We imposed size limitations for mapping certain features for purposes of legibility at map scale; the features on the map are intended to be representative of features in this region but should not be treated as a database for all occurrences of these features.
We mapped a total of 341 small craters between 200 and $500 \mathrm{~m}$ in diameter as point features. Small craters are distributed throughout the map area in most units, although they appear to be preserved less frequently in smooth-textured units such as parts of unit $\mathrm{Nnp}_{1}$. Line features trace the circular or quasi-circular rims of craters greater than $500 \mathrm{~m}$ in diameter. "Crest of crater rim" symbols indicate the relatively sharp and well-exposed rims of 56 simple craters as much as $7 \mathrm{~km}$ in diameter, including Sedona crater. Ten "crest of crater rim" segments trace the portion of the Jezero crater rim exposed within this map region. "Crest of buried crater" symbols indicate the four topographically subdued rims of craters whose walls and floor are no longer visible due to extensive infilling and (or) mantling.

We mapped megabreccia exposures as point features and identified them at 1:2,500 scale on supplemental HiRISE data (fig. 2; table 1). A total of 361 megabreccia points illustrate their representative distribution in the map area. Single points indicate individual megabreccia blocks and clusters (1:2,500 scale) of closely spaced megabreccia. Multiple points indicate areas of greater megabreccia frequency at map scale, particularly in areas where the megabreccia were more dispersed and individual blocks could not be feasibly mapped. The points in figure 2 represent where megabreccia is present but should not be taken as robust representations of megabreccia density or extent. The mapped points encompass megabreccia blocks from 10 to $100 \mathrm{~m}$ (lat $18.28^{\circ}$ N., long $77.30^{\circ}$ E.) in diameter. Megabreccias are found to occur only in units $\mathrm{Nnp}_{1}$ and $\mathrm{cr}$, which are the stratigraphically lowest units in the map area, and we interpreted unit $\mathrm{Nnp}_{1}$ to be the target rock for the Jezero impact. The megabreccias, therefore, represent preserved blocks of pre-Isidis or pre-Jezero crust.

"Channel" line features indicate long, sinuous depressions in Nili Planum that correspond to Neretva Vallis and Una Vallis. We interpreted these sinuous depressions as fluvial channels because of their branching nature and termination within basins in association with fan-shaped deposits $\left(\mathrm{NHjf}_{2}, \mathrm{Hnpf}\right.$ ) (Schon and others, 2012). Two branching line segments correspond to Una Vallis. Neretva Vallis consists of four channel-line segments in the map area; some of the segments relate to branching within the channel system, and portions of segments are obscured by infilling or deposition of unit Hnpf within Neretva Vallis (for example, at lat $18.61^{\circ} \mathrm{N}$., long $76.94^{\circ} \mathrm{E}$.; lat $18.56^{\circ} \mathrm{N}$., long $76.82^{\circ} \mathrm{E}$.). Two other channels that are outside of the immediate map area but are relevant to the geologic and aqueous history of the Jezero crater region are Sava Vallis, the northern inlet channel, and Pliva Vallis, the outlet channel (fig. 1). "Delta lobe front" line symbols on the main $\mathrm{NHjf}_{2}$ unit outline lobes of grouped channel deposits inferred to flow from common avulsion nodes.

"Lineament" symbols represent 98 lineations between 163 and $691 \mathrm{~m}$ in length, located radially around Sedona crater. Because of their association with Sedona's crater ejecta unit and the adjacent unit Nue, we interpreted that these radial lineaments formed during emplacement of the Sedona impact ejecta. "Ridge crest" symbols indicate 176 linear features between 153 and 2,837 $\mathrm{m}$ in length occurring in units $\mathrm{Nnp}_{1}$ and Nue. These ridges occur in positive relief relative to the surrounding topography (for example, lat $17.92^{\circ}$ N., long $77.18^{\circ}$ E.) and do not correspond to the raised edges of the light-toned, rugged Nue unit in southern Nili Planum. Constraining the origin of these linear features was limited by the 
map scale and the undetermined origin of the host unit $\left(\mathrm{Nnp}_{1}\right.$; see Description of Map Units), though we interpreted them as fractures that have been filled or cemented by mineralization, resulting in their relative resistance to erosion compared to surrounding rocks and causing these features to appear in positive relief. These ridges may be related to linear features in the light-toned rugged Nue unit, which contains large linear outcrops as long as 2 to $5 \mathrm{~km}$ (lat $17.78^{\circ} \mathrm{N}$., long $77.31^{\circ} \mathrm{E}$.), and the ridges located in unit $\mathrm{Nnp}_{1}$ may intersect unit Nue (for example, lat $18.19^{\circ} \mathrm{N}$., long $77.06^{\circ} \mathrm{E}$.).

Two surface features indicate textural variations in units $\mathrm{Nnp}_{1}, \mathrm{Njf}$, and Nue. The "ridged surface" occurs only in the portion of unit Nue mapped in the northeastern portion of the map area, within and around the north rim of Jezero crater. This surface consists of 31 discrete regions ranging in area from 0.02 to $82.67 \mathrm{~km}^{2}$, encompassing a total area of $167.69 \mathrm{~km}^{2}$. The ridged surface contains lineations as long as $400 \mathrm{~m}$ that are oriented northeast-southwest (fig. $3 A$ ). In contrast to other linear features in the map area, such as the "ridge crest" feature in unit $\mathrm{Nnp}_{1}$, the ridges in the ridged surface of unit Nue tend to be shorter - on the scale of a few hundred meters in length at mostand are more closely spaced (tens of meters to a hundred meters). These ridges are interpreted as yardangs (Day and Dorn, 2019). Although texturally distinct from the other parts of unit Nue, we could not confidently place the stratigraphic transition between the ridged surface and the rest of unit Nue, thus we mapped this surface texture as part of unit Nue and used the "ridged surface" to indicate the extent of this texture.

The "dark-colored mantling material" occurs in units $\mathrm{Nnp}_{1}$ and Njf. This feature consists of 256 discrete occurrences ranging in area from 0.04 to $75.95 \mathrm{~km}^{2}$, encompassing a total surface area of $418.5 \mathrm{~km}^{2}$. This feature corresponds to intermediate- to darktoned areas that appear consistently smooth textured over an areal extent of at least $0.02 \mathrm{~km}^{2}$ (fig. 5) but where the underlying bedrock unit is discernible or confidently interpreted. We interpreted this deposit as surficial cover overlying the more rugged bedrock typical of units $\mathrm{Nnp}_{1}$ and $\mathrm{Njf}$. Because this deposit occurs primarily in Jezero crater along the contact between units $\mathrm{Njf}$ and $\mathrm{NHjf}_{2}$, we hypothesize that the dark mantling deposit on top of unit $\mathrm{Njf}$ is an erosional lag derived from unit $\mathrm{NHjf}_{2}$ that was deposited as the delta eroded. The source of the dark mantling deposit overlying unit $\mathrm{Nnp}_{1}$ is not well constrained, but it may be sourced from the erosion of local rocks, potentially combined with airfall deposition given its wide areal distribution, draping of topography, and preferential accumulation in low-elevation areas.

\section{Age Determinations}

We determined relative age relations on the basis of crosscutting and superposition relations between map units. We did not derive absolute ages through crater counts on mapped geologic units for the reasons detailed below. Crater-count dating is a technique based on the principle that a newly emplaced surface contains no craters and, thereafter, accumulates craters at a rate extrapolated from the lunar chronology (for example, Crater Analysis Techniques Working Group, 1979; Hartmann and Neukum, 2001; Werner and Tanaka, 2011). Successful application of this technique relies on counting (1) only craters that postdate the surface of interest (2) on sufficiently large surface areas that yield reliable statistics (for example, Warner and others, 2015) and that are sufficiently crater retaining and relatively resistant to erosion. These factors proved difficult to determine in the map area and at the map scale.

For most craters at 1:75,000 publication scale, and even at 1:20,000 digital mapping scale, discerning whether an individual crater predates or postdates the geologic unit within which it occurs is difficult. For certain larger craters, such as Sedona and Angelica, an ejecta unit is visible and indicates that the crater postdates the surface and units into which it impacted. However, for most other craters, ejecta deposits are not visible and the temporal relation of the crater to the surface unit is unclear. Crater counts are also ideally performed over surface areas greater than $1,000 \mathrm{~km}^{2}$ and, most preferably, over $10,000 \mathrm{~km}^{2}$ (Warner and others, 2015) to minimize errors. However, the total area of our larger map units only ranges from $346 \mathrm{~km}^{2}$ (Njf) to $954 \mathrm{~km}^{2}$ (Nue). Many of the map units have also undergone significant erosion, as evidenced by inverted topographic features in several units that resulted in the removal of smaller craters from the surface and may skew any derived absolute ages (Smith and others, 2008).

These complications are demonstrated in the existing literature pertaining to this region. The Jezero floor (unit $\mathrm{Njf}$ ) has been mapped and age-dated by several workers who used varying methods and derived ages ranging from Noachian-Hesperian to Amazonian: $3.5 \mathrm{Ga}$ (Goudge and others, 2015), $2 \mathrm{Ga}$ (Shahrzad and others, 2019), 1.4 Ga (Schon and others, 2012). Given these difficulties, and the existing uncertainty of derived ages for some of the units in this region, we elected to derive relative ages rather than absolute ages and to reference previously published absolute ages as appropriate in the Geologic Summary. For Njf, which we interpreted to underlie fan units $\mathrm{NHjf}_{1}$ and $\mathrm{NHjf}_{2}$, a Late Noachian age was constrained by the age of the regional fluvial activity leading to the deposition of units $\mathrm{NHjf}_{1}$ and $\mathrm{NHjf}_{2}$, which ranges from Late Noachian to Early Hesperian (Fassett and Head, 2008; Ivanov and others, 2012; Mangold and others, 2020).

We describe the relative age relations between the remaining map units in the Methodology section and the Description of Map Units and summarize them in the Correlation of Map Units. Here, we discuss the relative timings of six prominent named craters that are large enough to have mappable crater ejecta, rim, or interior units and constrain the range of possible relative ages of these impact events. We note that, because no obvious ejecta units are associated with Jezero, the age of the Jezero impact can only be constrained from stratigraphic relations with other map units. This is discussed further in the Geologic Summary. Ulricehamn crater has a sharp crater rim at map scale but poorly defined ejecta and is located solely within unit $\mathrm{Nnp}_{1}$. We interpreted the lack of clear ejecta to have resulted from erosional degradation and (or) the Ulricehamn impact occurring during the emplacement of unit $\mathrm{Nnp}_{1}$, which may place its age as Middle Noachian. The Hartwell crater occurs within unit Njf and, though it has a well-defined crater rim, unit Njf appears to infill the area where Hartwell ejecta would have been deposited. Consequently, we interpreted the Hartwell impact to predate the emplacement of unit Njf, which constrains its impact age to the Middle or Late Noachian after the Jezero impact and before the emplacement of unit Njf. Sedona crater 
has an extensive ejecta unit overlying units $\mathrm{Nnp}_{1}$ and Nue and it appears to embay unit Nrb. These relations place the impact event during the Late Noachian or later, after Nrb emplacement. Marysville crater in Nili Planum does not have a clearly defined ejecta unit, but faint lineations in the adjacent unit $\mathrm{Nnp}_{1}$ appear to radiate from Marysville crater. Nearby occurrences of units Nue and $\mathrm{Nnp}_{2}$ also appear to terminate near the Marysville crater rim, suggesting that the impact disturbed pre-existing units Nue and $\mathrm{Nnp}_{2}$, placing the impact during the Late Noachian or later. Angelica crater contains an ejecta unit that appears to overlie unit Nue and disrupts the nearby portion of Neretva Vallis but also has a rim that is partially draped by unit Hnpf, suggesting an Early Hesperian impact after the majority of Neretva Vallis activity and before Hnpf deposition. Belva crater is located on top of unit $\mathrm{NHjf}_{2}$ and exposes deltaic strata within its crater walls, indicating that it occurred after deposition of unit $\mathrm{NHjf}_{2}$, during the Late Hesperian. We interpreted all six craters to have impacted prior to the emplacement of unit Aeb, which is the youngest map unit and occurs within these craters.

\section{Geologic Summary}

The geologic history of the Jezero crater and Nili Planum region is summarized graphically in the Correlation of Map Units and the cross sections and is described in detail in this section. This discussion is based primarily on the results of our mapping, with consideration of previously published hypotheses in the extensive literature for this region.

\section{Early to Middle Noachian}

During the Early Noachian prior to the Isidis basin impact, rocks and sediments that would eventually form parts of unit $\mathrm{Nnp}_{1}$ were emplaced in the map region. Discerning whether the pre-Isidis components of unit $\mathrm{Nnp}_{1}$ were volcanic and (or) sedimentary in origin is not possible without rover-scale observations of micro-scale textures and composition (for example, Martin and others, 2020). From orbital data, a lack of obvious volcanic vents or fluvial features associated with unit $\mathrm{Nnp}_{1}$ precludes distinguishing between these origins, and subsequent modification by the Isidis and Jezero impacts confounds the distinction of primary emplacement processes. The Isidis basin impact occurred about 3.85-4.06 Ga (Schultz and Frey, 1990; Werner, 2009), resulting in syn-Isidis deposition of ejecta units including megabreccia (Bramble and others, 2017; Scheller and Ehlmann, 2020) and the excavation, uplift, and deformation of Early Noachian crustal units in unit $\mathrm{Nnp}_{1}$. This impact produced a range of mapped $\mathrm{Nnp}_{1}$ textures that grade between one another (fig. 5): a highstanding mound-forming surface; a rugged high-relief surface; and a smooth, low-relief surface whose present-day appearance may result from subsequent erosion, mass wasting, and erosion from the rugged $\mathrm{Nnp}_{1}$ outcrops. The Isidis impact may have also initiated the formation of the linear ridges occurring in unit $\mathrm{Nnp}_{1}$. These ridges range to $2,837 \mathrm{~m}$ in length and can extend into unit Nue (for example, lat $18.19^{\circ}$ N., long $77.06^{\circ}$ E.; lat $17.86^{\circ}$ N., long $77.03^{\circ} \mathrm{E}$.). Studies have shown that these ridge geometries favor a mineralized fracture or clastic dike origin (Saper and Mustard, 2013; Bramble and others, 2017; Pascuzzo and others, 2019) over breccia or igneous-dike interpretations (Bramble and others, 2017). We interpreted that the Isidis impact generated fractures in unit $\mathrm{Nnp}_{1}$, which were later mineralized or facilitated clastic-dike intrusion, potentially during deposition of unit Nue.

The Jezero impact occurred after the Isidis impact during the Middle Noachian. The age of Jezero crater is constrained to Middle Noachian because it is older than the regionally extensive olivine-bearing deposit (Nue; MT in Goudge and others, 2015; FTU in Bramble and others, 2017) that drapes over the crater rim and has an estimated age of $3.82 \pm 0.07 \mathrm{Ga}$ (Kremer and others, 2019; Mandon and others, 2020). The Jezero impact may have further altered and deformed the surrounding unit $\mathrm{Nnp}_{1}$, resulting in warping and faulting of stratified rocks exposed on the Jezero crater rim in HiRISE images (for example, lat $18.46^{\circ} \mathrm{N}$., long $77.26^{\circ}$ E.; Stack and others, 2020). We interpreted that megabreccia throughout the map area (fig. 2) was produced by both the Isidis basin and Jezero impacts and may represent pre-Isidis and pre-Jezero components of unit $\mathrm{Nnp}_{1}$. Some megabreccia blocks contain banding or stratification at HiRISE scale (lat $17.88^{\circ} \mathrm{N}$., long $77.08^{\circ} \mathrm{E}$.) and may preserve remnants of pre-impact stratigraphy, although higher-resolution in situ investigations are needed to characterize whether these megabreccia preserve sedimentary or volcanic rocks (for example, Caudill and others, 2012).

During and after the Jezero impact, collapse of the transient crater rim resulted in the terraced walls (cross section $B-B^{\prime}$; Pilkington and Grieve, 1992) that are currently exposed as mounds that contain megabreccia (lat $18.15^{\circ} \mathrm{N}$., long $77.53^{\circ} \mathrm{E}$.; lat $18.29^{\circ} \mathrm{N}$., long $77.40^{\circ} \mathrm{E}$.) and underlie the subsequently deposited unit Nue. Though the Jezero impact surely generated ejecta, ejecta deposits associated with Jezero are notably unrecognizable in the map area. This suggests that Jezero's ejecta deposits were incorporated into the pre-existing $\mathrm{Nnp}_{1}$ unit and may be obscured by the deposition of unit Nue. During this Middle Noachian period and prior to the emplacement of unit Nue, the Ulricehamn impact may have also occurred, though its timing relative to the Jezero impact cannot be constrained because both impacted into unit $\mathrm{Nnp}_{1}$ and lack common stratigraphic relations with other map units.

After the Jezero crater impact, units Nle and Nue were emplaced throughout the map area; unit Nue was conformably deposited on unit Nle. We inferred that unit Nle shares a similar origin with unit Nue on the basis of their olivine-bearing composition (Goudge and others, 2015) and their often gradational shared contact. We therefore interpreted unit Nue, and unit Nle by proxy, as ash-fall or pyroclastic-surge deposits due to the draping morphology and banding observed in unit Nue (Kremer and others, 2019; Mandon and others, 2020). The banding and fracturing observed elsewhere in the regional olivine-bearing unit (Kremer and others, 2019) and the occurrence of unit Nue over the Isidisgenerated unit $\mathrm{Nnp}_{1}$ argue against an Isidis impact-melt origin as proposed by Mustard and others $(2007,2009)$. The draping of unit Nue (Kremer and others, 2019), which occurs at elevations ranging from $-2,707 \mathrm{~m}$ within Jezero to $-1,787 \mathrm{~m}$ in Nili Planum in the map area, also precludes a volcanic flow origin (Hamilton and Christensen, 2005). Unit Nle may also include contributions from lacustrine processes on the basis of its occurrence on 
the Jezero crater floor, where it is exposed primarily in erosional windows beneath unit Njf. Unit Nle may, therefore, represent airfall sediments deposited into a lake within Jezero, and (or) unit Nle was subsequently chemically altered or physically reworked by lacustrine processes, perhaps in the same lake environment that emplaced the fan deposits $\mathrm{NHjf}_{1}$ or $\mathrm{NH}_{2}$. By contrast, unit Nue is topographically and stratigraphically higher than unit Nle, occurs along the Jezero crater walls and in Nili Planum, and may not have been affected by lacustrine processes like unit Nle.

In Nili Planum, unit Nue was deposited on top of unit $\mathrm{Nnp}_{1}$, and has a possible emplacement age of $3.82 \pm 0.07 \mathrm{Ga}$ (Mandon and others, 2020). Unit Nue has a heavily cratered surface in northern Nili Planum and has a light-toned rugged surface in southern Nili Planum that often forms large linear outcrops with raised ridges along its margins (for example, lat $17.78^{\circ} \mathrm{N}$., long $77.31^{\circ} \mathrm{E}$.). The formation of these linear features in unit Nue may coincide with the formation of the raised linear ridges in unit $\mathrm{Nnp}_{1}$ (for example, lat $18.19^{\circ} \mathrm{N}$., long $77.06^{\circ} \mathrm{E}$.; lat $17.86^{\circ} \mathrm{N}$., long $77.03^{\circ}$ E.), which Pascuzzo and others (2019) interpreted as mineralized fractures or clastic dike intrusions that exploited fractures generated by the Isidis impact. We interpreted that the linear occurrences of unit Nue may have formed through similar infilling of pre-existing fractures, and subsequent cementation of unit Nue may have made it more resistant to erosion, resulting in the formation of the raised ridges along the margins of unit Nue in southern Nili Planum.

\section{Late Noachian to Early Hesperian}

Unit Nrb was subsequently emplaced on top of unit Nue during the Late Noachian, after erosion of units Nue and Nle. Unit Nrb occurs throughout Nili Planum and along the northern Jezero crater rim, and the sides of these mounds sometimes expose portions of unit Nue that are topographically higher than adjacent, continuous outcrops of unit Nue, suggesting that unit Nrb was emplaced on top of unit Nue (fig. 6). We interpreted that there is a nonconformable contact between units Nue and Nrb because it occurs at different elevations (cross section $B-B^{\prime}$ ). The largest exposures of unit Nrb were mapped at map scale but, at HiRISE scale, we also observed smaller mounds that overlie unit Nue throughout the map area (for example, lat $17.87^{\circ} \mathrm{N}$., long $77.25^{\circ} \mathrm{E}$.; lat $18.10^{\circ} \mathrm{N}$., long $77.31^{\circ} \mathrm{E}$.), suggesting that unit Nrb was formerly a more extensive deposit that eroded after emplacement to its current mound-forming surface. The origin of unit $\mathrm{Nrb}$ is uncertain, because it may have eroded as much as 30-70 $\mathrm{m}$ based on comparison of the present-day elevation of unit Nrb compared to exposures of unit Nue (for example, lat $17.75^{\circ}$ N., long $77.11^{\circ}$ E.; lat $18.69^{\circ}$ N., long $77.67^{\circ}$ E.). The Nrb mounds do not appear to be stratified except for a few instances that may exhibit subtle, coarse stratification at HiRISE scale (lat $17.88^{\circ}$ N., long $77.18^{\circ}$ E.; lat $17.86^{\circ}$ N., long $77.09^{\circ}$ E.), and there is no clear evidence for fluvial or volcanic contributions to their formation (for example, inverted channels or volcanic-flow morphologies associated with unit Nrb). By elimination, airfall deposition may be a possible origin for unit Nrb, but overall we interpreted that a sedimentary or volcanic origin cannot be confidently determined based on these heavily eroded and isolated occurrences of unit Nrb.
After the widespread emplacement of units Nue and Nrb, we interpreted that erosion of these units occurred based on the isolated occurrences of unit Nrb and the slopes of unit Nrb exposing unit Nue that are topographically higher than adjacent eroded Nue outcrops (fig. 6). Eroded sediments may have collected in the local topographic lows of unit $\mathrm{Nnp}_{1}$, contributing to the smooth, dark textures that we mapped as a dark mantling deposit (fig. $5 B, C$ ). During this interval of time from the Middle to Late Noachian, the Hartwell crater also impacted the Jezero crater floor and its ejecta was subsequently covered by the emplacement of unit Njf.

Units $\mathrm{Njf}$ and $\mathrm{Nnp}_{2}$ were deposited in Jezero crater and Nili Planum, respectively, during the Late Noachian. Unit Njf was deposited solely within Jezero crater on the crater floor and has since been eroded in some locations to expose the underlying unit Nle (lat $18.44^{\circ} \mathrm{N}$., long $77.44^{\circ}$ E.; lat $18.33^{\circ} \mathrm{N}$., long $77.73^{\circ} \mathrm{E}$.). Coincident with the deposition of unit Njf in Jezero is the deposition of unit $\mathrm{Nnp}_{2}$ in Nili Planum on top of units Nue, $\mathrm{Nnp}_{1}$, and $\mathrm{cr}$. Unit $\mathrm{Nnp}_{2}$ most commonly overlies unit Nue, forming distinct mesa features throughout Nili Planum (fig. 4), although other occurrences of unit $\mathrm{Nnp}_{2}$ appear to directly overlie unit $\mathrm{Nnp}_{1}$ or $\mathrm{Cr}$ where unit Nue is not present or apparent. Units Njf and $\mathrm{Nnp}_{2}$ share many similar erosional characteristics, including rugged, heavily cratered surfaces and well-defined, low-relief lobate scarps along the unit margins. On the basis of these similarities, we interpreted that units $\mathrm{Njf}$ and $\mathrm{Nnp}_{2}$ are genetically related and formed by the same process, although we mapped them as separate units because their distinct geographic occurrences on the Jezero crater floor and in Nili Planum allow the possibility of distinct depositional origins or chemical alteration or physical reworking of unit Njf by subsequent lacustrine processes during the deposition of units $\mathrm{NHjf}_{1}$ and $\mathrm{NHjf}_{2}$. Occurrences of unit $\mathrm{Nnp}_{2}$ span $241 \mathrm{~m}$ of elevation range $(-2,067$ to $-1,826 \mathrm{~m}$ ) within the map area and more than $1 \mathrm{~km}$ of elevation range within the larger northwestern Isidis basin (Sun and Stack, 2019). A fluvial or volcanic-flow origin would require significant erosion to produce the present-day remnants of unit $\mathrm{Nnp}_{2}$ with more than $1 \mathrm{~km}$ of elevation difference across large spatial distances in the larger northwestern Isidis basin (Sun and Stack, 2019), therefore we interpreted unit $\mathrm{Nnp}_{2}$ to be a clastic deposit, such as a volcanic ash or eolian airfall deposit. Such a deposit would have draped pre-existing topography at different elevation ranges and would explain why unit $\mathrm{Nnp}_{2}$ presently occurs on the Jezero crater rim (lat $18.39^{\circ}$ N., long $77.27^{\circ}$ E.). Banding or stratification visible along some margins (for example, lat $17.87^{\circ} \mathrm{N}$., long $77.09^{\circ} \mathrm{E}$.) suggests that deposition may have occurred in multiple, localized episodes. Based on the similarities between units $\mathrm{Njf}$ and $\mathrm{Nnp}_{2}$, we favor a similar ash or airfall origin for unit $\mathrm{Njf}$ as well, in contrast to the volcanic flow origin favored by Schon and others (2012) and Goudge and others (2015). We interpreted that both units $\mathrm{Nnp}_{2}$ and $\mathrm{Njf}$ also have similar emplacement ages. A wide range of crater count-derived ages have been reported for unit $\mathrm{Njf}$, ranging from Noachian-Hesperian to Amazonian: 3.5 Ga (Goudge and others, 2015), $2 \mathrm{Ga}$ (Shahrzad and others, 2019), 1.4 Ga (Schon and others, 2012). We interpreted unit Njf to have been emplaced before the deposition of fan units $\mathrm{NHjf}_{1}$ and $\mathrm{NHjf}_{2}$, which represent regional fluvial activity that is dated to the Late Noachian and Early Hesperian (Fassett and Head, 2008; Ivanov and others, 2012; Mangold and others, 2020), thereby placing unit $\mathrm{Njf}$, and therefore unit $\mathrm{Nnp}_{2}$, emplacement during the Late Noachian. 
Notable impact events during the Late Noachian include the Sedona and Marysville impacts. The Sedona impact produced an ejecta unit overlying units $\mathrm{Nnp}_{1}$ and Nue and embaying unit Nrb, placing the impact event during the Late Noachian or later. The Marysville impact occurred after the emplacement of units Nue and $\mathrm{Nnp}_{2}$, disrupting occurrences of unit Nue and $\mathrm{Nnp}_{2}$ in the target region and placing the Marysville impact during the Late Noachian or later.

After the emplacement of units $\mathrm{Njf}$ and $\mathrm{Nnp}_{2}$, fluvial or alluvial and deltaic processes deposited the fan units, $\mathrm{NHjf}_{1}, \mathrm{NHjf}_{2}$, and Hnpf, which are associated with fan-shaped landforms and nearby channels, Neretva and Una Valles. Within Jezero crater, unit $\mathrm{NHjf}_{1}$ was the first to be deposited, and currently it occurs in the northwest quadrant of the Jezero crater floor. Subsequent deposition emplaced unit $\mathrm{NH}_{2}$, which currently occurs along Jezero's western crater floor. Several distinct lobes defined by ridgeswhich we interpreted as fluvial channels - that originate from common avulsion nodes are discernible within unit $\mathrm{NHjf}_{2}$ (fig. 7). We inferred unit $\mathrm{NHjf}_{1}$ to be older than unit $\mathrm{NHjf}_{2}$ on the basis of its greater distance from the Neretva Vallis inlet channel and its lower elevation, especially where unit $\mathrm{NHjf}_{2}$ is deposited on top of unit $\mathrm{NHjf}_{1}$ (lat $18.58^{\circ} \mathrm{N}$., long $77.48^{\circ} \mathrm{E}$.). In line with previous studies, we favored a deltaic and (or) lacustrine origin for units $\mathrm{NHjf}_{1}$ and $\mathrm{NHjf}_{2}$, based on the presence of both inlet and outlet channels that indicate a hydrologically open lake environment (for example, Fassett and Head, 2005; Schon and others, 2012; Goudge and others, 2015, 2017, 2018). Though the full range of morphological and stratigraphic features that have been used by previous studies to support a deltaic origin for unit $\mathrm{NHjf}_{2}$ are not resolvable at the map scale, we made no new observations that would refute the depositional interpretation favored by past studies. In contrast, we did not find compelling evidence to support previous interpretations that unit $\mathrm{NHjf}_{1}$ was deposited via the northern Sava Vallis inlet channel (Goudge and others, 2015). We did not observe any fluvial features immediately near unit $\mathrm{NHjf}_{1}$ other than unit $\mathrm{NH}_{2}$, which is contiguous with an outcrop of unit $\mathrm{NHjf}_{1}$ (lat $18.58^{\circ} \mathrm{N}$., long $77.48^{\circ}$ E.), that would support a depositional connection between unit $\mathrm{NHjf}_{1}$ and the northern Sava Vallis inlet channel. We also interpreted arcuate ridges in the southwestern exposure of unit $\mathrm{NHjf}_{1}$ (lat $18.59^{\circ} \mathrm{N}$., long $77.47^{\circ}$ E.) as inverted channels that suggest transportation from the western Neretva Vallis channel.

We interpreted that unit $\mathrm{NHjf}_{1}$ was deposited on top of unit Njf during the Late Noachian, with deposition of unit $\mathrm{NH}_{2}$ following thereafter and potentially spanning the Late Noachian to the Early Hesperian. Several episodes of deposition are preserved in unit $\mathrm{NHjf}_{2}$ as distinct delta lobes that can be traced back to common avulsion nodes and show crosscutting relations (fig. 7). Conformable deposition between units $\mathrm{Njf}, \mathrm{NHjf}_{1}$, and $\mathrm{NHjf}_{2}$ is difficult to assess because the contact between units $\mathrm{Njf}$ and $\mathrm{NHjf}_{2}$ is obscured by a dark mantling deposit, and the contact between units $\mathrm{NHjf}_{1}$ and $\mathrm{NHjf}_{2}$ is approximate, with no visible stratification within or between the two fan units at map scale (lat $18.58^{\circ} \mathrm{N}$., long $77.48^{\circ}$ E.). The initial deposition of unit $\mathrm{NHjf}_{2}$ may have been substantially more extensive than that preserved in Jezero crater today. After deposition of unit $\mathrm{NHjf}_{2}$, subsequent erosion left remnant mounds, mapped here as unit $\mathrm{NHjf}_{2}$, toward the center of the Jezero crater floor (lat $18.47^{\circ}$ N., long $77.50^{\circ}$ E.). Erosional lag, derived from the erosion of the $\mathrm{NH}_{2}$ deposit, may have also contributed to the smooth, dark texture mapped as a dark mantling deposit on unit $\mathrm{Njf}$, which is concentrated near the contact between units $\mathrm{NHjf}_{2}$ and $\mathrm{Njf}$.

In Nili Planum, several exposures of unit Hnpf occur near Neretva Vallis and Una Vallis. These Hnpf deposits appear different than the Jezero interior fans $\left(\mathrm{NHjf}_{1}\right.$ and $\left.\mathrm{NHjf}_{2}\right)$, because they are darker in tone, have a smoother surface texture, and exhibit a comparatively less defined fan-shaped morphology. We interpreted that unit Hnpf was deposited during the Early Hesperian as one of the last widespread units to be emplaced in Nili Planum. One outcrop of $\mathrm{Hnpf}$ (lat $18.47^{\circ} \mathrm{N}$., long $76.89^{\circ} \mathrm{E}$.) has a clear apex marking the transition from an elongate channel deposit to a fan-shaped deposit. Portions of unit Hnpf appear to overlie and infill parts of Neretva Vallis (for example, lat $18.61^{\circ} \mathrm{N}$., long $76.94^{\circ}$ E.; lat $18.56^{\circ} \mathrm{N}$., long $76.82^{\circ}$ E.) with minimal fluvial incision on unit Hnpf itself, suggesting that unit Hnpf represents the remnants of alluvial or fluvial deposits emplaced during the late stages of the Neretva Vallis system as deposition of unit $\mathrm{NHjf}_{2}$ waned. Outcrops of unit Hnpf near Una Vallis occur in two depressions, one at the end point for Una Vallis, and contain stratification at HiRISE scale (lat $18.33^{\circ} \mathrm{N}$., long $77.09^{\circ}$ E.). This alluvial or fluvial interpretation for unit Hnpf contrasts with the "dark, smooth volcanic unit" interpretation by Goudge and others (2015). The unit Hnpf's dark, smooth-textured appearance suggests that its present-day surface is covered by a dark sediment, which may have been emplaced as a mantling deposit or by erosion of higher strata of unit Hnpf, similar to the production of dark mantle on unit Njf near its contact with unit $\mathrm{NHjf}_{2}$.

We constrained two impact events in the map area in association with the fan deposits. Ejecta from the Angelica impact overlie unit Nue and also disrupt the portion of Neretva Vallis to the south of the crater. The Angelica crater rim is also partially draped by unit Hnpf. These relations suggest that the Angelica impact occurred toward the later stages of Neretva Vallis fluvial activity in the Early Hesperian, otherwise Neretva Vallis would be continuously incised into the Angelica ejecta. Within Jezero crater, the Belva impact occurred during or after the Hesperian after the emplacement of unit $\mathrm{NHjf}_{2}$, exposing deltaic strata within its crater walls.

\section{Late Hesperian to Late Amazonian}

We interpreted that most units in the map area had been deposited by the Late Hesperian, based on dating of regional fluvial activity to this period (Fassett and Head, 2008; Mangold and others, 2020). Subsequent erosion and mass wasting occurred from the Late Hesperian to the present day, forming some of the textural variations observed in several units and mapped as surface features. Eolian erosion formed the ridged surface in the northeastern portion of unit Nue (fig. $3 A$ ) and the ridges are interpreted as yardangs (Day and Dorn, 2019). Erosion of local or regional units continued to contribute to the deposition of the dark-colored mantle overlying units $\mathrm{Njf}$ and $\mathrm{Nnp}_{1}$ and collecting in topographically lower regions. In particular, continued erosion of the fan units $\mathrm{NH}_{2}$ and $\mathrm{Hnpf}$ may have produced erosional lag deposits that contribute to the dark smooth textures present along the western portion of unit $\mathrm{Njf}$ and on the surface of unit Hnpf, respectively. Fan unit $\mathrm{NHjf}_{2}$ may have continued to erode substantially, leaving only a few remnant deposits on unit Njf (lat $18.47^{\circ} \mathrm{N}$., long $77.50^{\circ}$ E.). Throughout the 
Amazonian, erosion and eolian transport processes contributed to the formation of the eolian unit Aeb, which overlies many of the aforementioned geologic units and is interpreted as the youngest unit deposited in the map area. Unit Aeb is interpreted to be composed of transverse eolian ridges (Day and Dorn, 2019), whose bedforms are oriented orthogonal to prevailing wind directions (Balme and others, 2008). The bedforms in the map area are primarily oriented north-south, implying dominantly east-west wind directions (Day and Dorn, 2019). Unit su was emplaced on top of the other map units, typically occurring along slopes or collecting in local topographic lows and is marked by a smooth surface texture at map scale. The origin and depositional timing of unit su is unclear, and it may represent deposition at different times, by different processes, in different parts of the map area throughout the geologic timeline of the region. Occurrences of unit su on the slopes of crater rims and other high-standing features may be due to mass wasting of local high-relief outcrops. The presence of unit su within local topographic lows may also represent the residual accumulation of sand, pebbles, and cobbles resulting from erosion. Unit su may also have a genetic relation to the dark mantling deposit, particularly for occurrences overlying unit $\mathrm{Nnp}_{1}$ in Nili Planum. Given the wide areal distribution, occurrence at a range of elevations, and preferential accumulation in topographic lows, components of unit su and the dark mantling deposit may also reflect widespread deposition via air fall.

\section{Conclusions}

This map represents the first, large-scale, continuous geologic map spanning both Jezero crater and Nili Planum using high-resolution images. It provides a regional geologic framework for future in situ investigations by the Perseverance rover at Jezero crater and connects two localities that have been hypothesized to represent different surface and subsurface habitable environments. Building on previous maps and studies cited in this text, the results from this map advance our understanding of the Jezero crater and Nili Planum region in the following ways:

1. In addition to informing the geologic history of this region, the geologic units mapped throughout this map area serve as proxies for associated mineralogic composition in areas where no orbital spectroscopic data are available. High-resolution orbital mineralogic data, such as those supplied by the MRO CRISM instrument in targeted mode (Murchie and others, 2007), provide an important resource for rover mission planning, as demonstrated by the Mars Exploration Rovers, Spirit and Opportunity, and the Mars Science Laboratory Curiosity rover missions. High-resolution mineralogic data is comparatively absent in the vicinity of the the Midway ellipse, an $8.5 \times 8 \mathrm{~km}$ area centered at lat $18.3^{\circ} \mathrm{N}$., long $77.0^{\circ} \mathrm{E}$. that was a candidate ellipse for Mars 2020 and is a potential future destination for the Perseverance rover after Jezero crater (Fourth landing site workshop for the Mars 2020 rover mission, 2018) that had not been mapped as part of a regional map until now. Several geologic map units can be considered proxies for mineralogy on the basis of their strong correlation with particular mineral compositions, for example, low-calcium pyroxene and $\mathrm{Fe} / \mathrm{Mg}$ phyllosilicate with the smooth Nili Planum unit $1\left(\mathrm{Nnp}_{1}\right.$; Bramble and others, 2017; Pascuzzo and others, 2019), olivine and variable carbonate with the lower and upper etched units Nle and Nue (Goudge and others, 2015; Bramble and others, 2017), and mafic compositions with the Jezero floor unit Njf and Nili Planum unit 2 ( $\mathrm{Nnp}_{2}$; Goudge and others, 2015; Bramble and others, 2017). These associations allow mineralogy to be reasonably inferred in regions lacking orbital mineralogic data where the host geologic units have been mapped. This information is important because rocks bearing hydrated minerals like Fe/Mg phyllosilicate and carbonate are considered important astrobiological targets for investigation and potential sampling with the Perseverance rover (for example, Horgan and others, 2020). Confirming the origins of these units and their complete mineralogy will ultimately require analyses from higher resolution instruments on the Perseverance rover and from returned samples, but the interpretations from our mapping provide the regional geologic framework for future local in situ observations.

2. This map delineates several previously unmapped surface textures in the map region, further highlighting the role of erosion in shaping the rocks and sediments that the Perseverance rover may encounter. Smooth surface textures, inferred to represent mass wasting, erosional lag, or mantling deposits, are mapped in the Jezero floor unit (Njf) and Nili Planum unit $1\left(\mathrm{Nnp}_{1}\right)$ and are characteristic of the Nili Planum fan unit (Hnpf) and smooth unit (su). Ridged surface textures are recognized in the upper etched unit (Nue) and represent yardangs in that unit (Day and Dorn, 2019).

3. We interpreted that the Jezero floor unit (Njf) and Nili Planum unit $2\left(\mathrm{Nnp}_{2}\right)$ share a common origin such as a volcanic ash or eolian airfall deposit, contrary to previous interpretations of a volcanic flow for unit Njf (Schon and others, 2012; Goudge and others, 2015). Based on the shared erosional characteristics between units $\mathrm{Njf}$ and $\mathrm{Nnp}_{2}$, including rugged, cratered surfaces with lobate margins, and the occurrence of unit $\mathrm{Nnp}_{2}$ with over $1 \mathrm{~km}$ of elevation range (Sun and Stack, 2019), we interpreted both units $\mathrm{Njf}$ and $\mathrm{Nnp}_{2}$ to represent an airfall deposit that draped pre-existing topography, including the west rim of Jezero crater. Whether unit Njf is an ash deposit or lava flow carries different implications for the use of samples collected by the Perseverance rover in calibrating the Mars crater chronology (Grant and others, 2018).

4. We present a revised timing of fluvial events in the map area. We interpreted that the fan units $\mathrm{NHjf}_{1}$ and $\mathrm{NHjf}_{2}$ were deposited after the emplacement of the Jezero floor unit (Njf) and that the older unit $\mathrm{NHjf}_{1}$ was deposited from Neretva Vallis and not Sava Vallis, in contrast to previous interpretations (Goudge and others, 2015). In Nili Planum, we identify fan deposits (Hnpf) in and around Neretva and Una Valles that represents younger sedimentation as fluvial input into Jezero crater waned during the Early Hesperian.

5. This map shows a mound-forming unit Nrb that exposes the upper etched unit (Nue) along its slopes and that had not been previously mapped as occurring stratigraphically higher 
than unit Nue. The occurrence of Nrb mounds above unit Nue throughout the map area implies erosion, on the order of $30-70 \mathrm{~m}$, of a potentially more contiguous unit in this region. In contrast, we identified megabreccia within mounds along the south and west margins of the Jezero crater walls and interpreted these mounds to be remnants of transient crater rim collapse during the Jezero impact.

6. We derived relative ages, based on superposition relations, for six notable impact craters other than Jezero in the map area: Ulricehamn, Hartwell, Sedona, Marysville, Angelica, and Belva craters.

7. This mapping reinforced the connection between linear ridges in unit $\mathrm{Nnp}_{1}$ and adjacent occurrences of unit Nue bearing margins characterized by raised ridges in southern Nili Planum (Bramble and others, 2017; Pascuzzo and others, 2019). Both raised features may have formed through infilling of pre-existing fractures generated by the Isidis impact, and subsequent cementation and erosion resulted in their present-day high-relief topography.

\section{References Cited}

Baker, V.R., 1982, The channels of Mars: Austin, University of Texas Press.

Balme, M., Berman, D.C., Bourke, M.C., and Zimbelman, J.R., 2008, Transverse aeolian ridges (TARs) on Mars: Geomorphology, v. 101, no. 4, p. 703-720, https://doi.org/10.1016/j. geomorph.2008.03.011.

Bibring, J.-P., Langevin, Y., Mustard, J.F., Poulet, F., Arvidson, R., Gendrin, A., and others, 2006, Global mineralogical and aqueous Mars history derived from OMEGA/Mars Express data: Science, v. 312, no. 5772, p. 400-404, https://doi.org/10.1126/ science. 1122659 .

Bramble, M.S., Mustard, J.F., and Salvatore, M.R., 2017, The geological history of northeast Syrtis Major, Mars: Icarus, v. 293, p. 66-93, https://doi.org/10.1016/j.icarus.2017.03.030.

Carr, M.H., and Clow, G.D., 1981, Martian channels and valleys - Their characteristics, distribution, and age: Icarus, v. 48, no. 1, p. 91-117, https://doi.org/10.1016/00191035(81)90156-1.

Caudill, C.M., Tornabene, L.L., McEwen, A.S., Byrne, S., Ojha, L., and Mattson, S., 2012, Layered megablocks in the central uplifts of impact craters: Icarus, v. 221, no. 2, p. 710-720, https://doi.org/10.1016/j.icarus.2012.08.033.

Christensen, P.R., and others, 2004, The Thermal Emission Imaging System (THEMIS) for the Mars 2001 Odyssey mission: Space Science Review, v. 110, p. 85-130.

Christensen, P.R., Fergason, R.L., Edwards, C.S., and Hill, J., 2013, THEMIS-derived thermal inertia mosaic of MarsProduct description and science results [abs.]: 44th Lunar and Planetary Science Conference, March 18-22, 2013, contr. no. 1719 , p. 2822.

Cofield, S.M., and Stack, K.M., 2018, Geologic mapping and stratigraphic analysis of a candidate Mars 2020 landing site-

\section{Acknowledgments}

We are extremely grateful to Jeff Schroeder of the Jet Propulsion Laboratory for his help in assembling the completed map package, including combining the two map halves from Vivian Z. Sun and Kathryn M. Stack, finalizing shapefiles, annotating the map and associated components, and digitizing figures. We also thank U.S. Geological Survey Astrogeology map coordinators, James Skinner and Corey Fortezzo, for their assistance throughout the mapping and review process, as well as two reviewers for their thorough, constructive, and thoughtful feedback that greatly improved the map package. Thanks also to Cathy Quantin-Nataf (Universite de Lyon) and Fred Calef (Jet Propulsion Laboratory) for discussions, and Nathan Williams (Jet Propulsion Laboratory) for assistance with the supplemental HiRISE dataset. This research was carried out at the Jet Propulsion Laboratory, California Institute of Technology, under a contract with the National Aeronautics and Space Administration, Planetary Archiving, Restoration, and Tools (PDART) program grant 80NM0018F0612.

Jezero crater, Mars [abs.]: 49th Lunar and Planetary Science Conference 2018, contr. no. 2083, p. 2563.

Crater Analysis Techniques Working Group, 1979, Standard techniques for presentation and analysis of crater sizefrequency data: Icarus, v. 37, no. 2, p. 467-474, https://doi. org/10.1016/0019-1035(79)90009-5.

Day, M., and Dorn, T., 2019, Wind in Jezero crater, Mars: Geophysical Research Letters, v. 46, no. 6, p. 3099-3107, https:// doi.org/10.1029/2019GL082218.

Edwards, C.S., Nowicki, K.J., Christensen, P.R., Hill, J., Gorelick, N., and Murray, K., 2011, Mosaicking of global planetary image datasets - 1. Techniques and data processing for Thermal Emission Imaging System (THEMIS) multi-spectral data: Journal of Geophysical Research_Planets, v. 116, no. E10, http:// doi.org/10.1029/2010JE003755.

Ehlmann, B.L., and Mustard, J.F., 2012, An in-situ record of major environmental transitions on early Mars at Northeast Syrtis Major: Geophysical Research Letters, v. 39, no. 11, https://doi. org/10.1029/2012GL051594.

Ehlmann, B.L., Mustard, J.F., Fassett, C.I., Schon, S.C., Head, J.W., Des Marais, D.J., and others, 2008b, Clay minerals in delta deposits and organic preservation potential on Mars: Nature Geoscience, v. 1, no. 6, p. 355-358, https://doi. org/10.1038/ngeo207.

Ehlmann, B.L., Mustard, J.F., Murchie, S.L., Poulet, F., Bishop, J.L., Brown, A.J., and others, 2008a, Orbital identification of carbonate-bearing rocks on Mars: Science, v, 322, no. 5909, p. 1828-1832, https://doi.org/10.1126/science.1164759.

Ehlmann, B.L., Mustard, J.F., Swayze, G.A., Clark, R.N., Bishop, J.L., Poulet, F., and others, 2009, Identification of hydrated silicate minerals on Mars using MRO-CRISM - Geologic context near Nili Fossae and implications for aqueous alteration: Journal of Geophysical Research_Planets, v. 114, no. E2, https://doi.org/10.1029/2009JE003339. 
Fassett, C.I., and Head, J.W., 2005, Fluvial sedimentary deposits on Mars-Ancient deltas in a crater lake in the Nili Fossae region: Geophysical Research Letters, v. 32, no. 14., https://doi. org/10.1029/2005GL023456.

Fassett, C.I., and Head, J.W., 2008, The timing of martian valley network activity - Constraints from buffered crater counting: Icarus, v. 195, no. 1, p. 61-89, https://doi.org/10.1016/j. icarus.2007.12.009.

Fergason, R.L., Christensen, P.R., and Kieffer, H.H., 2006, Highresolution thermal inertia derived from the Thermal Emission Imaging System (THEMIS) - Thermal model and applications: Journal of Geophysical Research-Planets, v. 111, E1, https:// doi.org/10.1029/2006JE002735.

Fergason, R.L., Hare, T.M., Kirk, R.L., Piqueux, S., Galuzska, D.M., Golombek, M.P., Otero, R.E., and Redding, B.L., 2017, Mars 2020 landing site evaluation-Slope and physical property assessment [abs.]: Lunar and Planetary Conference 1964, contr. 2163.

Fergason, R.L, Hare, T.M., and Laura, J., 2018, Mars MGS MOLA - MEX HRSC blended DEM at global 200m v2: U.S. Geological Survey, Astrogeology PDS Annex, http://bit.ly/ HRSC_MOLA_Blend_v0.

Golombek, M., Grant, J., Kipp, D., Vasavada, A., Kirk, R., Fergason, R., and others, 2012, Selection of the Mars science laboratory landing site: Space Science Reviews, v. 170, no. 1, 641-737, https://doi.org/10.1007/s11214-012-9916-y.

Goudge, T.A., Milliken, R.E., Head, J.W., Mustard, J.F., and Fassett, C.I., 2017, Sedimentological evidence for a deltaic origin of the western fan deposit in Jezero crater, Mars, and implications for future exploration: Earth and Planetary Science Letters, v. 458, p. 357-365, https://doi.org/10.1016/j. epsl.2016.10.056.

Goudge, T.A., Mohrig, D., Cardenas, B.T., Hughes, C.M., and Fassett, C.I., 2018, Stratigraphy and paleohydrology of delta channel deposits, Jezero crater, Mars: Icarus, v. 301, p. 58-75, https://doi.org/10.1016/j.icarus.2017.09.034.

Goudge, T.A., Mustard, J.F., Head, J.W., Fassett, C.I., and Wiseman, S.M., 2015, Assessing the mineralogy of the watershed and fan deposits of the Jezero crater paleolake system, Mars: Journal of Geophysical Research-Planets, v. 120, no. 4, https://doi.org/10.1002/2014JE004782.

Grant, J.A., Golombek, M.P., Wilson, S.A., Farley, K.A., Williford, K.H., and Chen, A., 2018, The science process for selecting the landing site for the 2020 Mars rover: Planetary and Space Science, v. 164, p. 106-126, https://doi.org/10.1016/j. pss.2018.07.001.

Greeley, R., and Guest, J.E., 1987, Geologic map of the eastern equatorial region of Mars: U.S. Geological Survey map I-1802-B, scale 1:15,000,000, https://doi.org/10.3133/ i1802B.

Hamilton, V.E., and Christensen, P.R., 2005, Evidence for extensive, olivine-rich bedrock on Mars: Geology, v. 33, no. 6, p. 433-436, https://doi.org/10.1130/G21258.1.

Hartmann W.K., and Neukum G., 2001, Cratering chronology and the evolution of Mars, in Kallenbach R., Geiss J., and Hartmann W.K., eds., Chronology and evolution of Mars: Springer, Space Sciences Series of ISSI, v. 12., https://doi.org/10.1007/978-94017-1035-0_6.
Hiesinger, H., and Head, J.W., 2004, The Syrtis Major volcanic province, Mars - Synthesis from Mars Global Surveyor data: Journal of Geophysical Research-Planets, v. 109, no. E1, https://doi.org/10.1029/2003JE002143.

Horgan, B.H.N., Anderson, R.B., Dromart, G., Amador, E.S., and Rice, M.S., 2020, The mineral diversity of Jezero crater-Evidence for possible lacustrine carbonates on Mars: Icarus, v. 339, no. 113526, https://doi.org/10.1016/j.icarus.2019.113526.

Ivanov, M.A., Hiesinger, H., Erkeling, G., Hielscher, F.J., and Reiss, D., 2012, Major episodes of geologic history of Isidis Planitia on Mars: Icarus, v. 218, no. 1, p. 24-46, https://doi. org/10.1016/j.icarus.2011.11.029.

Kremer, C.H., Mustard, J.F., and Bramble, M.S., 2019, A widespread olivine-rich ash deposit on Mars: Geology, v. 47, no. 7, p. 677-681, https://doi.org/10.1130/G45563.1.

Malin, M.C., and others, 2007, Context Camera Investigation on board the Mars Reconnaissance Orbiter: Journal of Geophysical Research-Planets, v. 112, no. E5, https://doi. org/10.1029/2006JE002808.

Mandon, L., Quantin-Nataf, C., Thollot, P., Mangold, N., Lozac'h, L., Dromart, G., Beck, P., Dehouck, E., Breton, S., Millot, C., and Volat, M., 2020, Refining the age, emplacement, and alteration scenarios of the olivine-rich unit in the Nili Fossae region, Mars: Icarus, v. 336, p. 113436., https://doi.org/10.1016/j. icarus.2019.113436.

Mangold, N., Dromart, G., Ansan, V., Salese, F., Kleinhans, M.G., Massé, M., Quantin-Nataf, C., and Stack, K.M., 2020, Fluvial regimes, morphometry, and age of Jezero crater paleolake inlet valleys and their exobiological significance for the 2020 rover mission landing site: Astrobiology, v. 20, no. 8, http://doi. org/10.1089/ast.2019.2132.

Mangold, N., Poulet, F., Mustard, J.F., Bibring, J.-P., Gondet, B., Langevin, Y., and others, 2007, Mineralogy of the Nili Fossae region with OMEGA/Mars Express data-2. Aqueous alteration of the crust: Journal of Geophysical Research-Planets, v. 112, no. E8, https://doi.org/10.1029/2006JE002835.

Martin, P.E., Ehlmann, B.L., Thomas, N.H., Wiens, R.C., Hollis, J.J.R., Beegle, L.W., and others, 2020, Studies of a lacustrinevolcanic Mars analogic field site with Mars-2020-likeinstruments: Earth and Space Science, v. 7, no. 2, https://doi. org/10.1029/2019EA000720.

McEwen, A.S., Eliason, E.M., Bergstrom, J.W., Bridges, N.T., Hansen, C.J., Delamere, W.A., and others, 2007, Mars Reconnaissance Orbiter's High Resolution Imaging Science Experiment (HiRISE): Journal of Geophysical Research-Planets, v. 112, no. E5, https://doi.org/10.1029/2005JE002605.

Meyer, J.D., and Grolier, M.J., 1977, Geologic map of the Syrtis Major quadrangle of Mars: U.S. Geological Survey Geologic Investigations Map I-995, https://doi.org/10.3133/i995.

Murchie, S., Arvidson, R., Bedini, P., Beisser, K., Bibring, J.-P., Bishop, J., and others, 2007, Compact Reconnaissance Imaging Spectrometer for Mars (CRISM) on Mars Reconnaissance Orbiter (MRO): Journal of Geophysical Research-Planets, v. 112, no. E5, https://doi.org/10.1029/2006JE002682.

Mustard, J.F., Ehlmann, B.L., and Murchie, S.L., 2009, Hydrothermal alteration constrained by mineral assemblages on Mars_-Evidence from craters near Syrtis Major [abs.]: American Geophysical Union Fall Meeting Abstracts, v. 13, no. 5. 
Mustard, J.F., Murchie, S.L., Pelkey, S.M., Ehlmann, B.L., Milliken, R.E., Grant, J.A., and others, 2008, Hydrated silicate minerals on Mars observed by the Mars Reconnaissance Orbiter CRISM instrument: Nature, v. 454, no. 7202, p. 305-309, https://doi.org/10.1038/nature07097.

Mustard, J.F., Poulet, F., Head, J.W., Mangold, N., Bibring, J.-P., Pelkey, S.M., and others, 2007, Mineralogy of the Nili Fossae region with OMEGA/Mars Express data-1. Ancient impact melt in the Isidis Basin and implications for the transition from the Noachian to Hesperian: Journal of Geophysical Research-Planets, v. 112, no. E8, https://doi. org/10.1029/2006JE002834.

Neukum, G., Ivanov, B., and Hartmann, W.K., 2001, Cratering records in the inner solar system in relation to the Lunar Reference System: Space Science Review, v. 96, p. 165-194, https:// doi.org/10.1023/A:1011945222010.

Neumann, G.A., Rowlands, D.D., Lemoine, F.G., Smith, D.E., and Zuber, M.T., 2001, Crossover analysis of Mars Orbiter Laser Altimeter data: Journal of Geophysical Research, v. 106, no. E10, p. 23753-23768, https://doi. org/10.1029/2000JE001381.

Nimmo, F., and Tanaka, K., 2005, Early crustal evolution of Mars: Annual Review of Earth and Planetary Sciences, v. 33, no. 1, p. 133-161, https://doi.org/10.1146/annurev. earth.33.092203.122637.

Pascuzzo, A.C., Mustard, J.F., Kremer, C.H., and Ebinger, E., 2019, The formation of irregular polygonal ridge networks, Nili Fossae, Mars - Implications for extensive subsurface channelized fluid flow in the Noachian: Icarus, v. 319, p. 852-868, https://doi.org/10.1016/j.icarus.2018.10.020.

Pieri, D.C., 1980, Martian valleys; morphology, distribution, age, and origin: Science, v. 210, no. 4472, p. 895-897, https://doi. org/10.1126/science.210.4472.895.

Pilkington, M., and Grieve, R.A.F., 1992, The geophysical signature of terrestrial impact craters: Reviews of Geophysics, v. 30, no. 2, p. 161-181. https://doi.org/10.1029/92RG00192.

Ruff, S.W., 2017, Investigating the floor of paleolake Jezero by way of Gusev crater [abs.]: Fourth Lunar and Planetary Science Conference 2017, contr. 3076.

Salvatore, M.R., Goudge, T.A., Bramble, M.S., Edwards, C.S., Bandfield, J.L., Amador, E.S., and others, 2018, Bulk mineralogy of the NE Syrtis and Jezero crater regions of Mars derived through thermal infrared spectral analyses: Icarus, v. 301, p. 76-96, https://doi.org/10.1016/j.icarus.2017.09.019.

Saper, L., and Mustard, J.F., 2013, Extensive linear ridge networks in Nili Fossae and Nilosyrtis, Mars - Implications for fluid flow in the ancient crust: Geophysical Research Letters, v. 40, p. 245-249, https://doi.org/10.1002/grl.50106.

Scheller, E.L., and Ehlmann, B.L., 2020, Composition, stratigraphy, and geological history of the Noachian basement surrounding the Isidis impact basin: Journal of Geophysical Research, v. 125, no. 7, https://doi.org/10.1029/2019JE006190.

Schon, S.C., Head, J.W., and Fassett, C.I., 2012, An overfilled lacustrine system and progradational delta in Jezero crater, Mars-
Implications for Noachian climate: Planetary and Space Science, v. 67, no. 1, p. 28-45, https://doi.org/10.1016/j.pss.2012.02.003.

Schultz, R.A., and Frey, H.V., 1990, A new survey of multiring impact basins on Mars: Journal of Geophysical ResearchSolid Earth, v. 95, no. B9, 14175-14189, https://doi. org/10.1029/JB095iB09p14175.

Scott, D.H., and Carr, M.H., 1978, Geologic map of Mars: U.S. Geological Survey Miscellaneous Investigations Series Map I-1083, scale 1:25,000,000, https://doi.org/10.3133/i1083.

Shahrzad, S., Kinch, K.M., Goudge, T.A., Fassett, C.I., Needham, D.H., Quantin-Nataf, C., and Knudsen, C.P., 2019, Crater Statistics on the dark-toned, mafic floor unit in Jezero Crater, Mars: Geophysical Research Letters, v. 46, no. 5, p. 2408-2416, https://doi.org/10.1029/2018GL081402.

Smith, M.R., Gillespie, A.R., and Montgomery, D.R., 2008, Effect of obliteration on crater-count chronologies for Martian surfaces: Geophysical Research Letters, v. 35, no. 10, https://doi. org/10.1029/2008GL033538.

Squyres, S.W., and Kasting, J.F., 1994, Early Mars-How warm and how wet?: Science, v. 265, no. 5173, p. 744-749, https:// doi.org/10.1126/science.265.5173.744.

Stack, K.M., and others, 2020, Geologic map of the Perseverance landing site by the Mars 2020 Science Team [abs.]: Planetary Geologic Mappers Meeting 2020, contr. 2357, p. 7017.

Sun, V.Z., and Stack, K.M., 2018, Geomorphic mapping of the basement unit within the northeast Syrtis Major Mars 2020 landing ellipse [abs.]: 49th Lunar and Planetary Science Conference 2018, contr. 2083, p. 2179.

Sun, V.Z., and Stack, K.M., 2019, Understanding the continuity of regional units in the Mars 2020 Jezero and Northeast Syrtis regions - Implications for the origin of the mafic unit(s) [abs.]: 50th Lunar and Planetary Science Conference 2019, contr. 2132, p. 2271

Tanaka, K.L., Robbins, S.J., Fortezzo, C.M., Skinner, J.A. Jr., and Hare, T.M., 2014, The digital global geologic map of MarsChronostratigraphic ages, topographic and crater morphologic characteristics, and updated resurfacing history: Planetary and Space Science, v. 95, p. 11-24, https://doi.org/10.1016/j. pss.2013.03.006.

U.S. Geological Survey, 2006, FGDC digital cartographic standard for geologic map symbolization (postscript implementation): U.S. Geological Survey Techniques and Methods 11-A2, https://pubs.usgs.gov/tm/2006/11A02/.

Warner, N.H., Gupta, S., Calef, F., Grindrod, P., Boll, N., and Goddard, K., 2015, Minimum effective area for high resolution crater counting of martian terrains: Icarus, v. 245, p. 198-240, https://doi.org/10.1016/j.icarus.2014.09.024.

Werner, S., 2009, The global martian volcanic evolutionary history: Icarus, v. 201, no. 1, p. 44-68, https://doi.org/10.1016/j. icarus.2008.12.019.

Werner, S.C., and Tanaka, K.L., 2011, Redefinition of the craterdensity and absolute-age boundaries for the chronostratigraphic system of Mars: Icarus, v. 215, no. 2, p. 603-607, https://doi. org/10.1016/j.icarus.2011.07.024. 